\title{
Methodologies and approaches for the analysis of cell-nanoparticle interactions
}

\section{Advanced Review}

Authors:

\begin{tabular}{l} 
Angela Ivask* \\
ORCID. 0000-0003-3451-7211, Laboratory of Environmental Toxicology, National \\
Institute of Chemical Physics and Biophysics, Tallinn, Estonia; Future Industries Institute, \\
University of South Australia, Mawson Lakes, South Australia, Australia, \\
angela.ivask@kbfi.ee \\
\hline Andrew J. Mitchell \\
ORCID. 0000-0003-4454-853X, Materials Characterisation and Fabrication Platform, \\
University of Melbourne, Melbourne, Australia, andrew.mitchell1@unimelb.edu.au \\
\hline Anzhela Malysheva \\
Future Industries Institute, University of South Australia, Mawson Lakes, South \\
Australia, Australia, anzhela.malysheva@mymail.unisa.edu.au \\
\hline Nicolas H. Voelcker \\
ORCID. 0000-0002-1536-7804, Drug Delivery, Disposition and Dynamics, Monash \\
Institute of Pharmaceutical Sciences, Monash University, Parkville, Victoria, Australia, \\
nicolas.voelcker@monash.edu \\
Enzo Lombi \\
ORCID. 0000-0003-3384-0375, Future Industries Institute, University of South Australia, \\
Mawson Lakes, South Australia, Australia, enzo.lombi@unisa.edu.au
\end{tabular}

\section{Abstract}

How to study nanoparticle-cell interactions is the key question that puzzles researchers in the fields of nanomedicine as well as in nanotoxicology. In nanotoxicology, the amount of nanoparticles internalized by the cells or bound to the external surfaces of cells determines the toxic profile of those particles. In medical applications, cellular uptake and binding of medically effective nanoparticles decides their efficacy. Despite the importance of understanding the extent and mode of nanoparticle-cell interactions, these processes are underinvestigated, mainly due to the lack of suitable user-friendly methodologies. Here we discuss the advantages and limitations of currently available (and most advanced) microscopic, spectroscopic and other bioanalytical methods that could be used to assess cell-nanoparticle interactions either qualitatively or quantitatively. Special

This is the author manuscript accepted for publication and has undergone full peer review but has not been through the copyediting, typesetting, pagination and proofreading process, which may lead to differences between this version and the Version of Record. Please cite this article as doi: 10.1002/wnan.1486 
emphasis is given to the methods that enable analysis and identification of nanoparticles at singlecell level, and allow intracellular localization and speciation analysis of nanoparticles.

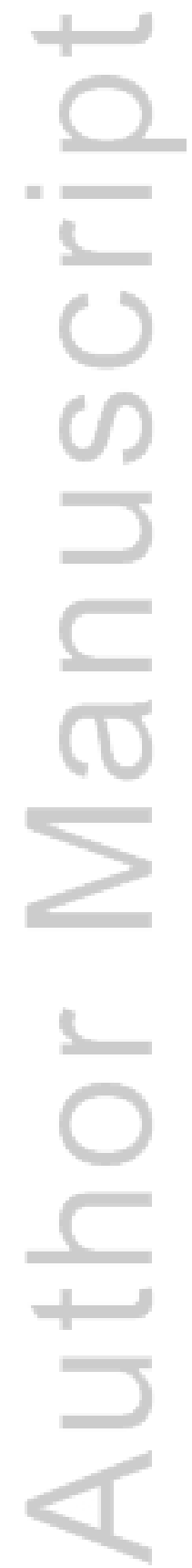

This article is protected by copyright. All rights reserved. 


\section{Graphical/Visual Abstract and Caption}

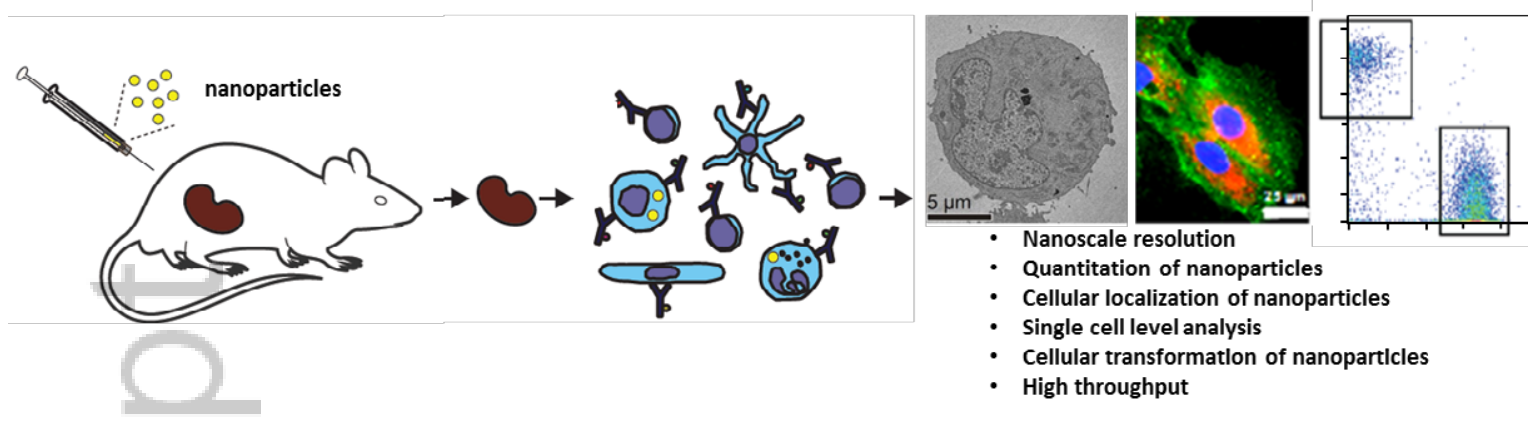

A variety of microscopy- and spectroscopy-based, and other bioanalytical methods may be used to assess nanoparticle-cell associations.

\section{Table of Contents}

Introduction

2. Methods for qualitative and quantitative analysis of cell-associated nanoparticles

2.2. Qualitative analysis of nanoparticle-cell interactions

2.2.1. Microscopy methods

Fluorescence microscopy

Dark-field microscopy

Electron microscopy

2.2.3. Raman microspectroscopy

\subsubsection{Flow cytometry}

2.3. Quantitative analytical methods

2.3.1. Bulk analysis of cell-associated nanoparticles

Mass spectrometry-based methods

Time resolved ICP-MS

2.3.2 Analysis of cell-associated nanoparticles at single cell level

Laser ablation ICP-MS and laser desorption/ionization mass spectrometry

High-resolution secondary ion mass spectrometry (nanoSIMS)

Synchrotron based X-ray techniques for nanoparticle visualization in cells

Single cell ICP-MS and mass cytometry (time of flight mass spectrometry)

3. Methods to distinguish between cell surface bound and internalized nanoparticles

3.2. Chemical etching methods

4. Methods and approaches to assess cellular speciation of nanoparticles

4.1. Synchrotron methods

Conclusions 


\section{Introduction}

The enormous appeal of nanotechnology for various industrial and medical applications and the novel characteristics of the nanoscale materials $(1-100 \mathrm{~nm})$ have spurred the evolution of several new and exciting fields of research. The biomedical research has quickly taken over the drive of nanomaterial development for therapeutic applications, drug-delivery systems and imaging agents that exploit their unique properties. ${ }^{1}$ Evolutions of nanotechnology and nanomedicine have prompted us to investigate the basic principles of interactions between engineered nanoparticles and living organisms. Similarly to large macromolecular agglomerates and viruses, nanoparticles may not only interact with biological entities such as organs and tissues, but may also be able to cross the cellular barriers and be internalized by cells through various forms of endocytosis. ${ }^{2,3}$ Although this capacity of nanoparticles to cross biological barriers is advantageous for many therapeutic applications, concerns have been raised regarding their potential adverse effects. In order to evaluate the efficacy of nano-medicinals or to assess the toxicity of nanoscale materials, the extent of interactions between nanoparticles and biologicals (cells, tissues or organisms) that, needs to be determined, and processes that drive these interactions - investigated. Such task is not free of complications as the nature and extent of nano-bio interactions depend on both, the intrinsic properties of nanoparticles such as size, shape and crystallinity, the properties of the biological system they are exposed to, and the transformation of nanoparticles during the test, e.g., due to the formation of protein corona. ${ }^{4}$ Although its importance has been acknowledged by a number of authors $^{2,5-8}$, quantitative information on nanoparticle-cell interactions is rarely presented alongside nanomedical or nanotoxicological results. Most studies that discuss in vitro effects of nanoparticles refer to either mass-, volume- or surface area-based exposure concentrations. Analysis of nanoparticle uptake and biodistribution has received greater attention in in vivo studies since the ultimate goal of those studies is to assess the medically effective concentration of administered nanoparticles.

The scarcity of detailed investigations into the extent and mode of nanoparticle-cell interactions in both in vitro and in vivo studies is likely due to the lack of suitable user-friendly methodologies. An ideal methodology would require minimal sample preparation, allow sufficient resolution, perform quantitation and cellular localization of nanoparticles at the single cell level, and be capable of high sample throughput. Moreover, the methodology would ideally be independent of material properties and would not require fluorescent or radioactive labelling of nanoparticle. This review focuses on analytical methods that hold the potential to analyze and quantify cellnanoparticle interactions. Methods described therein mainly address cellular interactions with metal-based nanoparticles while less emphasis is being made on analysis of cellular association with carbon- or organic polymer-based nanoparticles due to the lack of suitable methods. Firstly, we will discuss visualization-based methods such as electron microscopy and fluorescence microscopy, which enable particle identification at cellular level but are qualitative and have low throughput. Next, we will outline the advantages of quantitative methods such as inductively coupled plasma mass spectrometry and atom absorption spectrometry in the analysis of nanoparticle-exposed cells. 
This discussion will be extended by introducing mass spectrometry-based methods and cytometry by time-of-flight mass spectrometry, which enable single cell level analysis of cell-associated (cell surface bound and internalized) nanoparticles. We will also tackle the issue of cellular localization of nanoparticles and discuss the methods available to distinguish between cell surface bound and internalized nanoparticles. Finally, we will present methods that can be used to follow intracellular fate and speciation of nanoparticles that, along with nanoparticle intracellular localization, are highly relevant for understanding their biological effects. It may be noted that most examples reported in this review on the use of the above-listed methods originate form in vitro studies, as very limited number of relevant in vivo studies has been published on this topic.

\section{Methods for qualitative and quantitative analysis of cell-associated nanoparticles}

Ideally, assessment of nanoparticle-cell interactions would be quantitative and allow single cell level analysis of cell-associated nanoparticles (by "cell-associated" we here refer to both, cell surface bound and intracellular nanoparticles). Some microscopy-based approaches (e.g., electron microscopy) offer sufficient resolution for the analysis at cellular level but are time consuming, mostly low throughput and in standard set-up are generally limited to qualitative analysis of nanoparticles in cells. Flow cytometry, which can be considered as an extension of fluorescence microscopy, allows higher sample throughput while still providing only qualitative information on cell-associated nanoparticles. Analytical mass spectrometry (MS)-based methods, which allow the collection of quantitative information on cell-associated nanoparticles, are useful only for metalbased nanoparticles and in standard analysis mode do not enable the analysis of nanoparticles at single cell level. Recently, new applications of MS methods such as laser ablation ICP-MS (LA-ICPMS), time-resolved ICP-MS (TR-ICP-MS), nano secondary lonization mass spectrometry (nanoSIMS), and mass cytometry (essentially flow cytometry combined with time of flight mass spectrometry, ToF-MS) have been introduced. The opportunities and limitations of these selected methods are discussed below and summarized in Table 1.

\subsection{Qualitative analysis of nanoparticle-cell interactions}

\subsubsection{Microscopy methods}

Microscopy methods are probably among the most widely used methods in cell biology, included in majority of studies on nano-bio interactions. Due to the limited resolution of light microscopy, which is determined by the wavelength of the light and Rayleigh resolution criterion ${ }^{9}$, only electron microscopy can be used for true nanoscale visualization. With certain reservations and technological improvements discussed below, dark-field and fluorescence microscopy have been extensively employed for visualization of nanosize particles.

Fluorescence microscopy

Due to its ease of use and ubiquity, fluorescence microscopy is most frequently applied to study nanoparticle-cell interactions. This approach is based on excitation of fluorescent molecules within 
the sample using a defined wavelength, and subsequent collection of the emitted, longer wavelength light. ${ }^{10}$ Thus, in order to be visualized, nanoparticles should be fluorescently tagged or intrinsically fluorescent, e.g., quantum dots. However, besides the fact that fluorescent labelling is not feasible for all nanoparticles, fluorescent labels may be released from the nanoparticles, ${ }^{11,12}$ the behaviour of tagged materials in biological systems may differ from that of the non-tagged ones, ${ }^{13,14}$ fluorescent label can be bleached or quenched ${ }^{15}$ and if multiple channels are used e.g., to visualize cellular compartments and nanoparticles, cross-talk between adjacent channels may take place.

The major advantage of using fluorescence microscopy is the ability to simultaneously visualize cellular compartments and, hence, study the subcellular localization of nanoparticles. This is illustrated in Figure 1 where Oliveira et al. ${ }^{16}$ labelled the nucleus and membrane structures of nanoparticle-exposed cells. As mentioned above, fluorescence microscopy results are qualitative and quantitative information on nanoparticles in cells is unavailable due to either the low number of cells that can be analyzed or insufficient resolution of the method. ${ }^{17}$ Yet some authors have attempted the quantitation of fluorescent nanoparticles based on fluorescence intensity after prior calibration with transmission electron microscopy. ${ }^{18}$ 
Table 1. Attributes and limitations of selected currently available methods for cell-nanoparticle analysis.

\begin{tabular}{|c|c|c|c|c|c|c|c|c|c|}
\hline+2 & $\begin{array}{l}\text { Nano-scale } \\
\text { resolution }\end{array}$ & $\begin{array}{l}\text { Nanoparticle } \\
\text { identification }\end{array}$ & $\begin{array}{l}\text { Nanoparticle } \\
\text { quantitation }\end{array}$ & $\begin{array}{c}\text { Nanoparticle } \\
\text { transformation }\end{array}$ & $\begin{array}{c}\text { Celluar } \\
\text { localization of } \\
\text { nanoparticles }\end{array}$ & $\begin{array}{c}\text { High } \\
\text { through- } \\
\text { put }\end{array}$ & $\begin{array}{l}\text { Single cell } \\
\text { analysis }\end{array}$ & $\begin{array}{l}\text { Live cell } \\
\text { analysis }\end{array}$ & $\begin{array}{c}\text { Sample } \\
\text { preservation }\end{array}$ \\
\hline $\begin{array}{l}\text { Fluorescence } \\
\text { microscopy }\end{array}$ & $-/+^{a}$ & + & - & $-/+^{b}$ & + & $-/+$ & + & + & + \\
\hline $\begin{array}{l}\text { Dark-field } \\
\text { microscopy }\end{array}$ & + & $+/-^{c}$ & - & $+/-^{c}$ & + & - & + & + & + \\
\hline $\begin{array}{l}\text { Raman } \\
\text { microscpectroscopy }\end{array}$ & $-/+^{d}$ & - & - & - & + & - & + & + & + \\
\hline $\begin{array}{l}\text { Electron } \\
\text { microscopy }\end{array}$ & + & + & - & $-/+^{e}$ & + & - & + & $-/+^{f}$ & $+/-$ \\
\hline Flow cytometry & - & + & $-/+^{g}$ & $-/+b$ & + & + & + & + & + \\
\hline $\begin{array}{l}\text { Mass spectrometry } \\
\text { (e.g., ICP-MS)** }\end{array}$ & - & - & + & - & $-/+^{h}$ & + & - & - & - \\
\hline $\begin{array}{l}\text { Laser ablation ICP- } \\
\text { MS** }\end{array}$ & + & - & + & - & $-/+^{h}$ & + & + & + & - \\
\hline $\begin{array}{l}\text { Time-resolved ICP- } \\
\text { MS ** }\end{array}$ & + & + & + & - & $-/+^{h}$ & + & + & + & - \\
\hline $\begin{array}{l}\text { nano Secondary } \\
\text { Ionization Mass } \\
\text { Spectrometry }\end{array}$ & + & + & - & - & + & - & + & + & - \\
\hline Mass cytometry** & + & + & + & - & $-/+^{h}$ & + & + & + & - \\
\hline $\begin{array}{l}\text { Synchrotron X-ray } \\
\text { absorption }\end{array}$ & + & + & - & + & $-/+^{h}$ & - & + & + & + \\
\hline
\end{tabular}

absorption 
$-/+$ or $+/$ - information can be obtained with certain reservations:

nanoscale resolution possible by surface enhanced raman spectroscopy

a nanoscale resolution possible when using superresolution mode

nanoparticle transformation is possible to track if the transformation affected NP morphology

${ }^{b}$ nanoparticle transformation is possible to track if the transformation affects NP fluorescence

' nanoparticle identification possible by parallel application of hyperspectral imaging

${ }^{f}$ liquid scanning transmission electron microscopy

${ }^{\mathrm{g}}$ possible after calibration of the method (see 2.2.2.)

possible after prior treatment e.g., using chemical etching methods

$* *$ analysis possible only for metal-containing nanoparticles

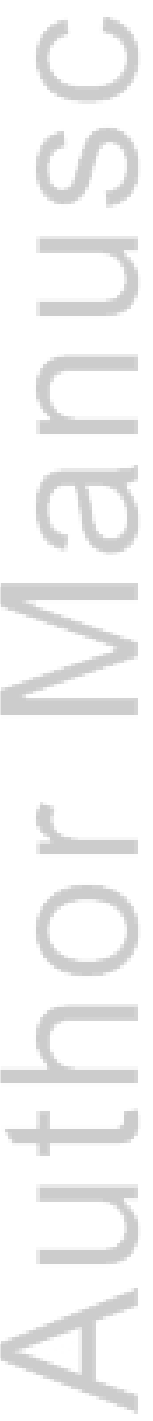

This article is protected by copyright. All rights reserved. 

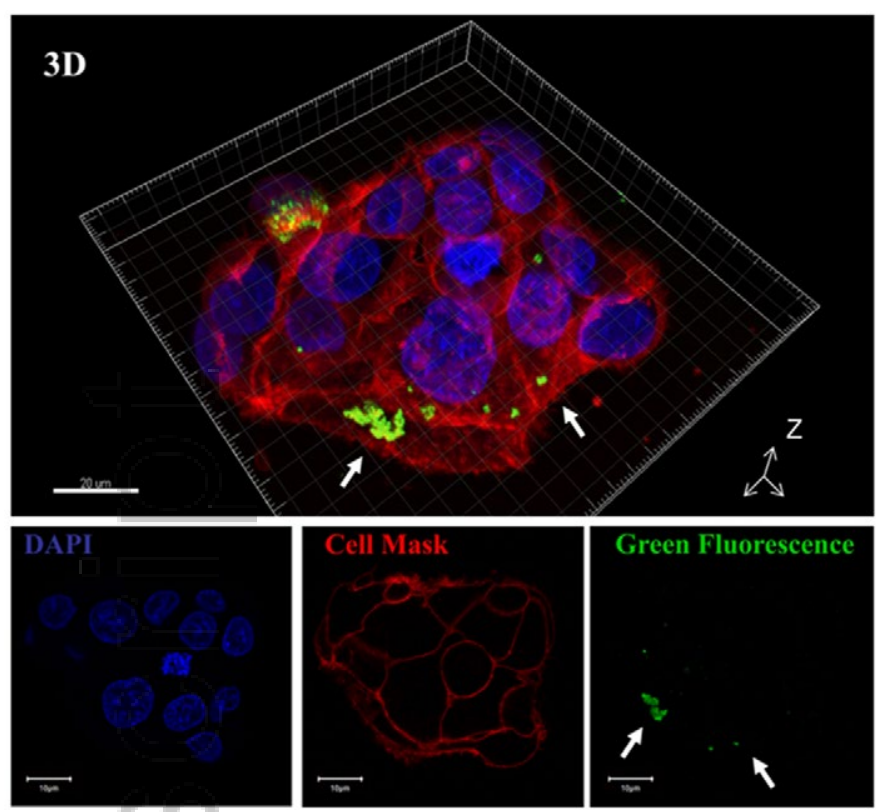

Figure 1. Example imaging of nanoparticles and their cellular localization using fluorescence microscopy. Green fluorescent Ag nanoparticles exposed to human HepG2 cells were stained with DAPI (blue, nuclei) and Cell Mask (red, membranes). Nanoparticles in cells are shown with white arrows. Figure is modified from Oliveira et al. ${ }^{16}$ C 2013 Oliveira et al.

With the motivation of visualizing and identifying single particles in cells super-resolution methods - stimulated emission depletion microscopy $(S T E D)^{19}$, photoactivated localization microscopy $(\text { PALM })^{20}$, stochastic optical reconstruction microscopy (STORM) ${ }^{21,22}$ and structured illumination microscopy (SIM) $)^{23}$ - have recently been developed. STED microscopy is based on the excitation of fluorophores by a focused light beam and an additional depletion light beam, which brings molecules back to the ground state by a process called stimulated emission ${ }^{19,24,25}$. The intensity profile of this additional beam at the focal plane is depleting the fluorescence near the edge of the focal spot and, therefore, significantly reduces the size of the fluorescence, improving the image resolution. SIM on the other hand uses sinusoidal shaped patterned illumination that generates a similarly shaped fluorescence emission pattern, which generates a saturated emission profile with narrow dark regions ${ }^{23}$. With these improvements, the resolution of fluorescence microscopy can be increased down to $\sim 100 \mathrm{~nm}$, which is $2-5$ times better than that of conventional fluorescence microscopy ${ }^{26}$ (Figure 2). 


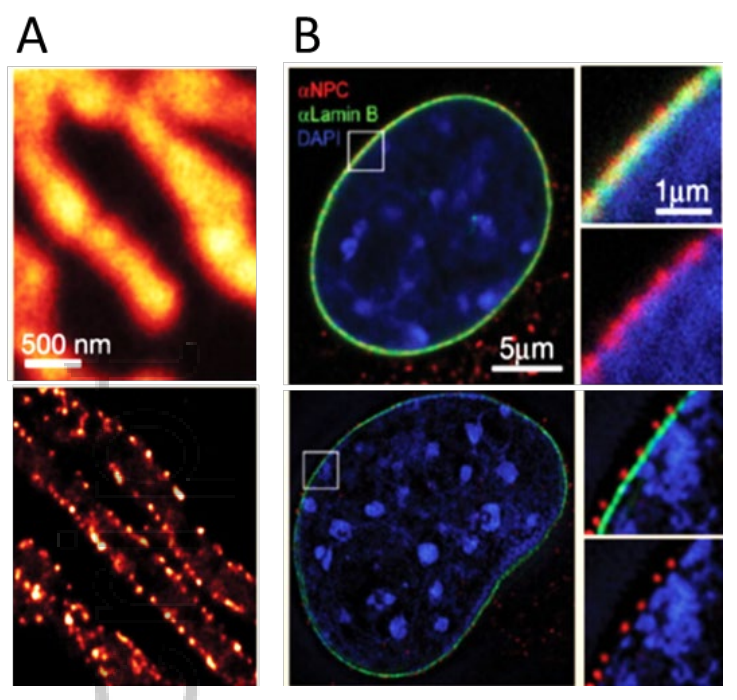

Figure 2. Improvement in resolution using super-resolution microscopes. (A) Outer membrane of mitochondria fluorescently immunolabeled against protein TOM20 imaged in confocal fluorescence microscope (up) and in STED microscope (down); adapted with permission from Schmidt et al. ${ }^{27}$ Copyright (2009) American Chemical Society. (B) Cell nucleus stained with DAPI (blue), Lamin B (green) and the nuclear pore complex (red) in confocal fluorescence microscope (up) and in SIM mode; adapted with permission from Schermelleh et al. ${ }^{28}$ C 2008 , American Association for the Advancement of Science.

\section{Dark-field microscopy}

Dark-field microscopy is an optical microscopy method in which an unscattered illumination beam is excluded and only structures that scatter light are visualized. Due to the high light-scattering ability of dense inorganic particulates, this methodology can be successfully used to visualize nanoparticles in soft biological tissues and cells. In addition to increasing the contrast of imaging, dark-field microscopy enables the visualization of smaller objects than bright-field microscopy ${ }^{29}$ and does not require specific labelling of cells or nanoparticles.

Dark-field microscopy has been used to visualize cellular interactions with Ag nanoparticles ${ }^{30}$ $\mathrm{Ag}$ and $\mathrm{CeO}_{2}$ nanoparticles with algal cells ${ }^{31,32}$ and the interactions of yeast Candida albicans with a series of metal nanoparticles. ${ }^{33}$ The method has been used in numerous studies to visualize the interactions between nanoparticles and mammalian cells in vitro but also in vivo. Anderson et al. ${ }^{35}$ used enhanced dark field microscopy to visualize nanoparticles in tissues of animals that were exposed to $20 \mathrm{~nm} \mathrm{Ag}$ and Roth et al. ${ }^{36}$ used this methodology to identify nanoparticles in animals pre-exposed to nanoparticulate metal oxide. Gibbs et al. evaluated the potential of a combination of dark-field and confocal laser scanning microscopy in 3D analysis of 50-6500 nm polystyrene and 30 $\mathrm{nm} \mathrm{TiO}_{2}$ nanoparticles in human lung cells. ${ }^{34}$ They used a specially optimized set-up that consisted of 
a confocal microscope equipped with a dark-field condenser and suitable lasers to visualize the cellular localization of $\mathrm{TiO}_{2}$ nanoparticles as shown in Figure 3.
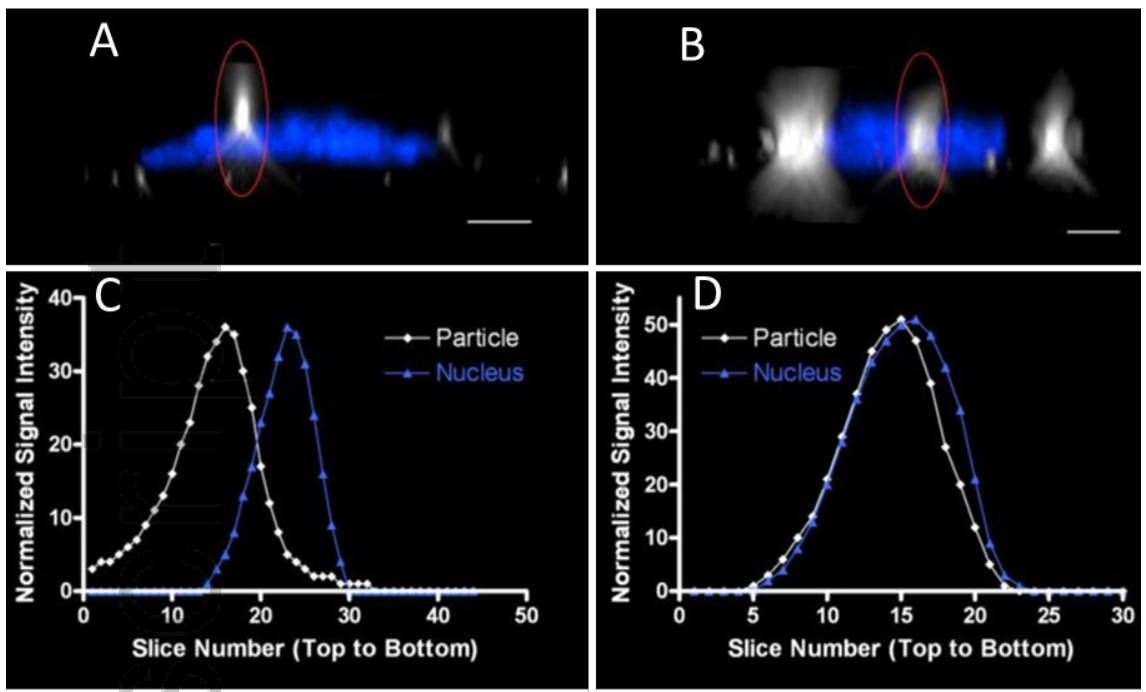

Figure 3. Simultaneous fluorescence and dark-field confocal scanning of $\mathrm{TiO}_{2}$ nanoparticle-exposed human bronchial epithelial BEAS 2B cells. Side view of cells exposed to $\mathrm{TiO}_{2}$ nanoparticles for $5 \mathrm{~min}$ (A) or $2 \mathrm{~h}$ (B). Scale bar $10 \mu \mathrm{m}$ and magnification 3000x. Nucleus is stained with blue fluorescent dye and nanoparticles appear as bright spots. Red circles indicated the area from which slices in z-axis (shown in $C$ and $D$ ) were created. Lower graphs illustrate positioning of nanoparticles and nucleus in $z$ axis in $A(C)$ and $B(D)$. Figure is from Gibbs-Flournoy et al. ${ }^{34}$ (c) Gibbs-Flournoy et al.; licensee BioMed Central Ltd. 2011.

A variation on this approach was performed by Klein et al. ${ }^{37}$, who used dark-field microscopy combined with electron microscopy. In their study dark field images were obtained in a transmission electron microscopy set-up by tilting the beam radially and collecting only scattered electrons. Images collected from nanoparticle-exposed bacterial (Bacillus subtilis) cells demonstrate that darker regions in TEM appear bright spots in dark-field mode thus, demonstrating the presence of nanoparticles in those samples.

One of the drawbacks of the dark-field microscopy is the potential interference from any light scattering particulate material. Therefore, specifically pre-cleaned slides and sample holders need to be used, and the sample has to be cleaned from any dust and unwanted particulates. Recently, dark-field imaging system has been equipped with a spectrograph, enabling the instrument to collect hyperspectral data. ${ }^{38}$ In this set-up, spectral information between 400 and $1000 \mathrm{~nm}$ from the sample is collected and spectral profiles of each pixel of the image allow mapping and identification of the sample material(s). ${ }^{39}$ Dark-field imaging together with hyperspectral imaging has been used to identify gold nanorods in human lung epithelial cells $\mathrm{A} 549^{40}$, Ag nanoparticles in macrophages $^{41}$, bioaccumulation of $\mathrm{Ag}$ nanoparticles in algal cells ${ }^{42}$, associations between $\mathrm{Ag}$ nanoparticles and bacterial cells ${ }^{43}$ and the potential of this method in visualizing and identifying 
nanoparticles in cells is evident. The apparent drawback related to hyperspectral imaging is the modification of the spectral profiles of nanoparticles occurring with change in their size of surface coating material ${ }^{44,45}$. This emphasizes the need for relevant hyperspectral libraries of the studied nanoparticles when identifying nanoparticles with hyperspectral imaging method.

\section{Electron microscopy}

Electron microscopy (EM) is the only microscopic method capable of visualizing single nanoparticles in cells. A further advantage of EM is that it does not require specifically tagged nanoparticles since any nanoscale material with higher electron density than cellular structures can be visualized. EM uses a beam of accelerated electrons (with wavelength less than $0.1 \mathrm{~nm}$, i.e., $1 \AA$ ) and can be used either to measure the transmission of those electrons through the sample (transmission electron microscope, TEM) or signals created due to the interactions between the electrons and the surface of the sample (scanning electron microscope, SEM) ${ }^{46}$ In the first case, the sample needs to be thin to allow the passage of electrons, while in the second case any sample can be viewed but only at its surface. Due to the small size of the electron beam, the resolution of electron microscopes is remarkable. In general, TEM has higher resolution than SEM and its resolution can reach $1 \AA$ or even lower, if specific magnetic lenses are used ${ }^{9}$, e.g., in high resolution TEM instruments. Usually, TEM and SEM imaging is performed in a vacuum environment and requires an extensive sample preparation (i.e., fixing and drying of the cells), which is labour intensive, time-consuming, and does not necessarily allow the analysis of dynamic processes that are occurring during nanoparticle-cell interactions. For TEM viewing, samples (e.g., nanoparticle-exposed cells) should be fixed and contrasted, embedded into a solid polymer matrix and sliced to thin sections (usually 70-100 nm thick). ${ }^{47}$ In addition to being time-consuming, this process includes a series of toxic chemicals (e.g., osmium tetroxide, lead citrate and uranyl acetate used for cellular contrasting) that can easily introduce artefacts when accidentally precipitating on the prepared samples. ${ }^{48}$ Thus, researchers are more frequently moving away from sample contrasting towards more native-state imaging in biological TEM. ${ }^{48}$ Sample preparation for SEM is more straightforward than for TEM but also involves a number of time-consuming steps, including sample dehydration and introduction of a coating to add surface conductivity. ${ }^{49}$

Two newer methodologies have been developed that simplify sample preparation for electron microscopy. Liquid scanning transmission electron microscopy (liquid STEM) introduced by Peckys and de Jonge ${ }^{51}$ allows TEM imaging of living cells inside a microfluidic chamber between silicon nitride membranes. This approach can be used for samples up to $10 \mu \mathrm{m}^{51}$ but presents one significant drawback: only nanoparticles themselves, but not cellular structures, can be visualized. Thus, for intracellular localization of nanoparticles the method needs to be used in parallel with optical or fluorescence microscopy. With environmental SEM (ESEM imaging of liquid samples does not require extensive sample preparation such as fixation, dehydration or application of conductive coating, as "wet" samples can be visualized. ${ }^{52}$ On the other hand, due to the absence of vacuum (and 
the presence of gas, usually water vapor) electrons in the visualization set-up are scattered and the resolution of this method is lower than that of conventional SEM.

Although EM is predominantly a qualitative method, some studies have attempted to quantify the imaged nanoparticles. For example, Elsaesser et al. ${ }^{50}$ presented a method to quantitatively measure $50 \mathrm{~nm}$ Au nanoparticles in cultured mammalian cells. Peckys and de Jonge ${ }^{51}$ presented EM image analysis that allowed them to count nanoparticles in cellular vesicles and, hence, evaluate the number of nanoparticles in each cell. Alternatively, Summers et al. performed 3D imaging of quantum dot-exposed osteocarcinoma cells followed by quantitation of nanoparticles in vesicular structures within cells. ${ }^{53}$ The authors prepared nanoparticle-exposed cell samples following normal TEM sample protocols, but analyzed sequential cross sections of the cells. This enabled them to create 3D visual images of individual cells (Figure 4). Furthermore, by calibrating the EM images with data obtained for the sample samples with fluorescence microscopy, they were able to calculate particle dose per cell.

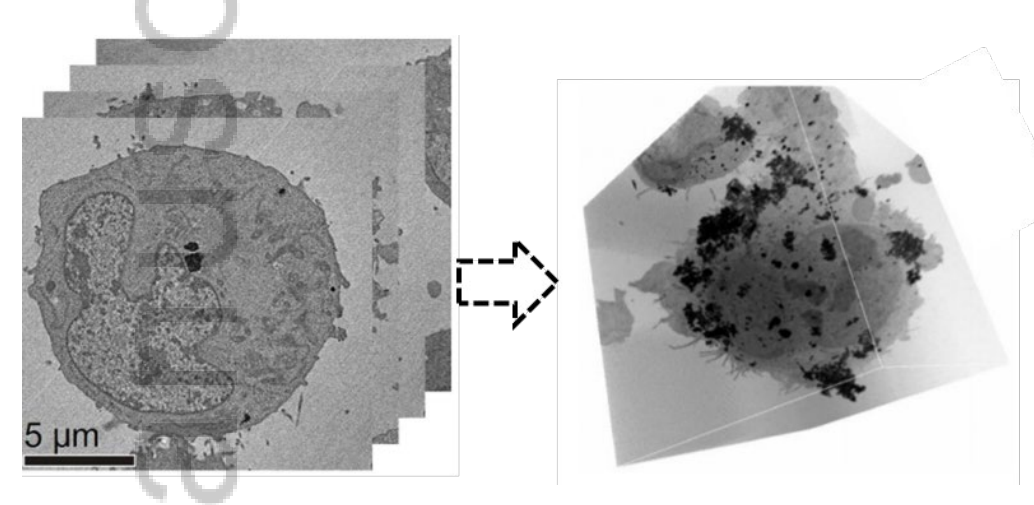

Figure 4. 3D reconstruction of 2D transmission electron microscope images. Visualization of intracellular quantum dots in human U-2 OS osteosarcoma cell line. Figure is modified from ${ }^{53}$ and $^{54}$. Copyright (c) 2013 American Chemical Society (Public Licence). (c) Microscopy Society of America 2014.

\subsubsection{Raman microspectroscopy}

Raman microspectroscopy is a powerful bioanalytical method which can provide substantial information regarding the chemical composition of a single cell without prior staining of labelling..$^{55,56}$ In this method, a monochromatic laser beam is applied to the sample and the interactions of this beam with the sample results in elastic scattering of the photons and loss of energy, termed Stokes shift. Based on the scattered photons, a spectrum in which each peak corresponds to one distinct molecular vibration is obtained and further analysis of those peaks allows to identify the molecular bonds together with their micro-environment. ${ }^{55}$ For optimal Raman shift, suitable excitation laser and image analysis should be used. As suggested by Schie and Huser, ${ }^{55}$ the most suitable for cellular applications is $532 \mathrm{~nm}$ in terms of signal intensity and optimal autofluorescence. There is also a 
possibility to perform Raman spectoscopy analysis in confocal mode resulting in 3D views of single cells. $^{55}$

Using Raman microscpectroscopy, Dorney et al. mapped the cellular localization of 50-100 $\mathrm{nm}$ polystyrene nanoparticles. ${ }^{14}$ The authors demonstrated that in addition to detecting and localizing intracellular nanoparticles, Raman spectroscopy coupled with multivariate analyses such as $\mathrm{K}$-means clustering analysis allows the assessment of changes in cell metabolism upon nanoparticle exposure. As the signals obtained from single cells with Raman microspectroscopy are usually weak, several methods for enhancement of signals have been developed. These methods include surface enhanced Raman scattering (SERS) that uses noble metal surfaces to enhance the signal up to million folds ${ }^{57}$ and coherent Raman scattering that enables fast and improved readout of chemical information from scattering images. ${ }^{58}$ SERS is probably more popular of the two for single cell analysis $^{59}$ and often plasmonic nanoparticles such as Au have been used as Raman signal enhancers. On the other hand, surface enhanced Raman spectroscopy has also been used to visualize intracellular nanoparticles. ${ }^{59}$ For example, Kneipp et al. ${ }^{60,61}$ used SERS to localize $<100 \mathrm{~nm} \mathrm{Au}$ nanoparticles inside the cells. However, as this method, similarly to fluorescent microscopy, relies on a laser beam and its spatial resolution is determined by the wavelength of the light used, at current state the resolution of Raman spectroscopy remains in the order of hundreds of nanometers. This may be one of the limiting issues in the application of Raman spectroscopy for the analysis of cellnanoparticle applications.

\subsubsection{Flow cytometry}

Flow cytometry is routinely used in biomedical research as a methodology capable of simultaneously measuring and analysing multiple physical characteristics of single events, usually cells, as they flow through a laser beam in a fluidics system. ${ }^{62}$ Single events (e.g., cells) in the sample may scatter the laser light, and any fluorescent molecules present on the particle emit fluorescence that is collected and transformed into electronic signals proportional to the intensity of the optical signals. With this method it is possible to measure the relative size, granularity (or internal complexity) and relative fluorescence intensity of each event (e.g., cell) in the sample. In order for nanoparticles to be detected by flow cytometry, either intrinsically fluorescent or fluorescently tagged nanoparticles need to be used. However, in contrast to fluorescence microscopy, flow cytometry enables quantitation of nanoparticle fluorescence but, unfortunately, not the nanoparticle mass or number. In order to make method more quantitative, toolsets that include the calibration of flow cytometer using prior measurement of the fluorescence of a known concentration of nanoparticles have been introduced. ${ }^{13,63}$ However, these methods are currently not commonly utilized and need further development. 

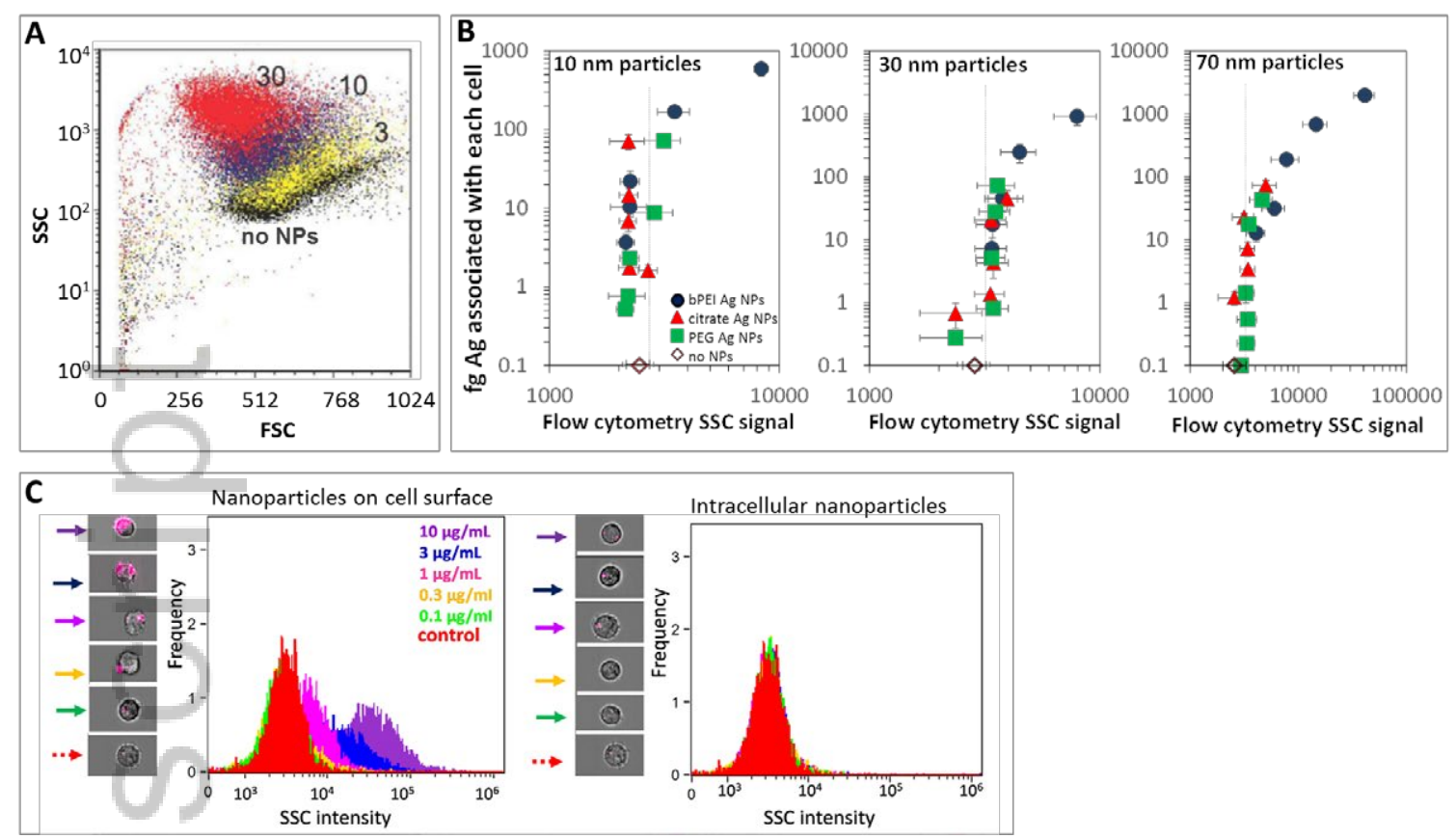

Figure 5. Analysis of cell-associated non-fluorescent nanoparticles by flow cytometry. (A) ARPE-19 human retinal pigment epithelial cells were exposed to $30-40 \mathrm{~nm} \mathrm{TiO}{ }_{2}$ nanoparticles at different concentrations ( $3-30 \mu \mathrm{g} / \mathrm{mL}$ as indicated) and analyzed with flow cytometry. Cell-associated nanoparticles can be inferred from increased side scatter signal (SSC-H) whereas cell size is measured with forward scatter (FSC) function; figure is from Zucker et al. ${ }^{64}$ Published 2010 Wiley-Liss, Inc. (B) correlation between flow cytometry side scatter signal (SSC), which measures cellular granularity, and mass of cell-associated Ag (from ICP-MS) in Ag nanoparticle-exposed cells. Human T-lymphocyte cells were exposed to Ag nanoparticles with different coatings: branched polyethylene imine (bPEI), citrate and polyethylene glycol (PEG) and different (10-70 nm) primary size. SSC signal of cells that were not exposed to Ag nanoparticles is shown for comparison. Dotted vertical line represents SSC value above which the signal was considered different from non-exposed cells. For $10 \mathrm{~nm}$ Ag NP exposed cells, only those which Ag content was above $100 \mathrm{fg}$ (10 $00010 \mathrm{~nm}$ particles per cell) were SSC positive; for $30 \mathrm{~nm} \mathrm{Ag} \mathrm{NP} \mathrm{exposed} \mathrm{cells} \mathrm{those} \mathrm{which} \mathrm{Ag} \mathrm{content} \mathrm{was}$ above $80 \mathrm{fg}$ Ag (200 $30 \mathrm{~nm}$ NPs per cell) were SSC positive; for $70 \mathrm{~nm} \mathrm{Ag} \mathrm{NP}$ exposed cells those which Ag content was above $20 \mathrm{fg}$ ( 5 NPs per cell) were SSC positive. Figure is based on data presented in Ivask et al. ${ }^{30}$ (C) SSC signal of cells with $70 \mathrm{~nm} \mathrm{Ag}$ particles attached to cell surface is shown on left image and SSC signal of cells with only intracellular nanoparticles is shown on right image. Exposure concentrations of Ag nanoparticles are indicated. Figure is from Ivask et al. ${ }^{30}(\mathrm{C}$ 2016 Elsevier B.V. All rights reserved.

Although analysis with flow cytometry traditionally requires fluorescent nanoparticles, several recent studies have employed flow cytometry to analyze cellular association of nonfluorescent nanoparticles. These studies have employed the side scatter (SSC) function of flow cytometry $^{30,64}$ which is typically used to identify cellular granularity (Figure $5 \mathrm{~A}$ ). As with the analysis of fluorescent nanoparticles, an important disadvantage to this approach is its poor quantitation 
power. To overcome this, some authors have introduced methods to calibrate the SSC signal of flow cytometer by parallel analysis of the samples with ICP-MS. ${ }^{30}$ They demonstrated that SSC was able to reliably detect cell-associated $10 \mathrm{~nm} \mathrm{Ag}$ nanoparticles from $\sim 100 \mathrm{fg} \mathrm{Ag}$ per cell (translated to 10000 nanoparticles per cell), cell-associated $30 \mathrm{~nm} \mathrm{Ag}$ nanoparticles from $\sim 80 \mathrm{fg}$ per cell (translated to 200 nanoparticles per cell) and cell-associated $70 \mathrm{~nm} \mathrm{Ag}$ nanoparticles from $\sim 20 \mathrm{fg}$ per cell (translated to 5 nanoparticles per cell) (Figure 5 B). Similarly, Zucker et al. ${ }^{64}$ showed that use of SSC was able to detect 5-10 30-40 nm $\mathrm{TiO}_{2}$ nanoparticles per cell. Although the majority flow cytometry studies employing SSC signals have concluded that the detected signal originates from intracellular nanoparticles, ${ }^{64-69}$ a recent study by Ivask et al. ${ }^{30}$ demonstrated that flow cytometry SSC allows only the detection of cell surface attached particles. Specifically, when these authors used a potassium hexacyanoferrate(III)/sodium thiosulfate-based etching procedure ${ }^{68}$ (see also section 3.2 ) to remove cell surface attached $\mathrm{Ag}$ nanoparticles (in quantitative terms up to $95 \%$ of cell-associated nanoparticles), they observed that nanoparticle-originated SSC signal of flow cytometry disappeared (Figure $5 \mathrm{C}$ ). This suggests that the origin of flow cytometry SSC signal from nanoparticle-exposed cells will need to be clarified further.

\subsection{Quantitative analytical methods}

Complementing the qualitative analysis methods described above with quantitative data on cellassociated nanoparticles is essential for generating a complete understanding of nano-bio interactions. In terms of nanoparticle quantitation, an ongoing matters of discussion is dosimetry. ${ }^{69,70}$ Since the onset of nano-bio sciences and nanotoxicology, there has not been a consensus as to whether nanoparticle mass, surface area or particle number is the best measure of the biologically active quantity of nanoparticles. ${ }^{71}$ While nanoparticle mass is the easiest to measure, it does not reflect the potential transformations of nanoparticles (e.g., agglomeration, aggregation, dissolution) that can take place during the test. Thus, for example, depending on particle size the same mass of nanoparticles may translate to different particle number and surface area. Considering the importance of particulate appearance of nanoparticles, particle number could be suggested as the most important quantitative measure for nanoparticles. On the other hand, it has been clearly demonstrated that nanoparticle surface area is responsible for the biological interactions of nanoparticles. ${ }^{72}$ Yet none of the quantitative methods described in the sections below is able to perform surface area-based quantitation of cell-associated nanoparticles. Furthermore, the number based quantitation of nanoparticles in biological systems is a challenging task and with certain reservations is likely to be performed only with time-resolved ICP-MS. Instead, almost all currently available analytical methods are able to perform mass-based quantitation of nanoparticles, as discussed below.

\subsubsection{Bulk analysis of cell-associated nanoparticles}

Mass spectrometry-based methods 
Mass spectrometry (MS) based analytical methods such as inductively coupled plasma mass spectroscopy (ICP-MS), atomic emission and optical emission mass spectrometry (AES and OES) are becoming increasingly popular in quantifying cell-associated nanoparticles. ${ }^{73,74}$ Although these methods are very sensitive with detection limits in the order of parts-per-billion and dynamic range is several orders of magnitude, ${ }^{75,76}$ their use is restricted to nanoparticles that are composed of MS relevant elements (e.g., using ICP-MS, 70 chemical elements can be measured ${ }^{77}$ ). It should also be mentioned that MS methods are not able to detect any changes in speciation that may take place during biological exposure but enable only elemental analysis. ICP-MS is a particularly appealing technology for examining interactions between nanoparticles and cells. Typically in ICP-MS, sample is introduced through a nebulizer and a spray chamber into a plasma torch, where it is instantaneously heated to $>7000^{\circ} \mathrm{K}$. This causes atomization of the sample, resulting in a cloud of positively-charged ions that is transported towards the detector. Sample preparation of cellassociated nanoparticles for ICP-MS analysis generally involves the separation of nanoparticleexposed cells from free-floating nanoparticles, followed by digestion of cells (Figure 6). This analysis provides information on the total concentration of the specified element in the sample without any knowledge of its form (dissolved or particulate) ${ }^{30,78,79}$ (Figure 6). In order to investigate whether the element is present in dissolved or particulate form, traditional digestive methods that dissolve the nanoparticle-exposed cells and tissues are not applicable. Instead, methods that allow preservation of nanoparticles throughout the extraction process should be used. Recently, several studies have presented enzymatic digestive protocols that allow the recovery of intact NPs from biological samples. ${ }^{80}{ }^{82}$ Nanoparticles in those samples can be subsequently quantified using particle-specific methods such as time-resolved ICP-MS as discussed below.

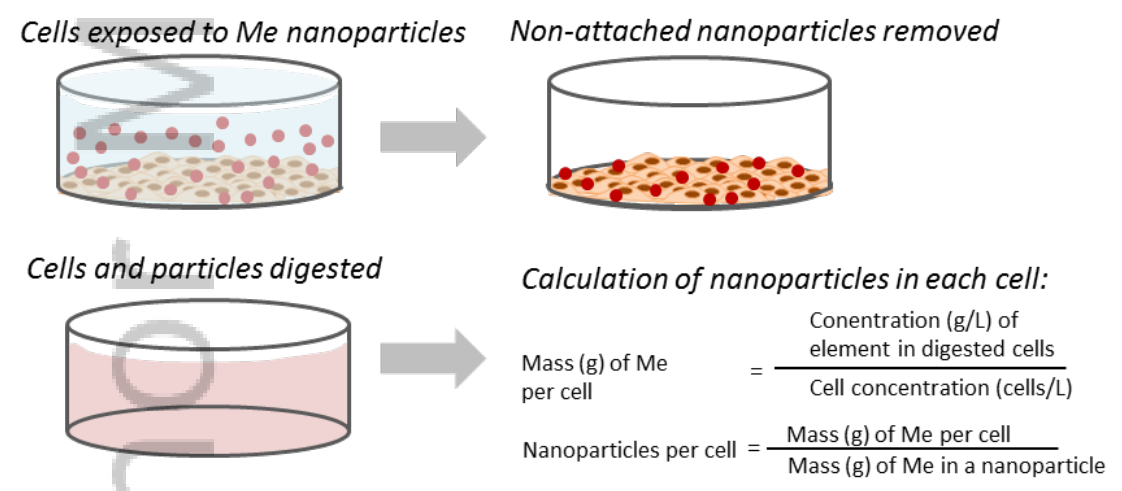

Figure 6. A general scheme for quantitation of cell-associated nanoparticles by mass spectrometry.

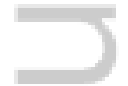

Time resolved ICP-MS

Time-resolved or single-particle ICP-MS (SP-ICP-MS) encompasses the analysis of particulates by a range of ICP-MS based technologies including ICP-Quadrupole Mass Spectrometry (Q-MS), ICP- 
Sector Field Mass Spectrometry (SF-MS) and ICP-Time-of-Flight Mass Spectrometry (TOF-MS) (reviewed in ${ }^{75,83,84}$ ). The main principle behind SP-ICP-MS is detection of a discrete pulse, originating from ionization of a single particle, utilizing short detection or dwell time. If the particle composition is known, the signal from a single particle event can be correlated to particle mass, and the number of signals detected in the sample - to particle number concentration. Today, SP-ICP-MS is of growing popularity for sensitive (detection limit in $\mathrm{ng} / \mathrm{L}$ range) characterization of nanoparticles ${ }^{85,86}$ in the field of environmental chemistry as well as nanotoxicology. So far, SP-ICP-MS has been used to analyze Ag-based NPs extracted from organisms ${ }^{87,88}$, tissues ${ }^{81,89}$ and to study the dynamics of Ag NPs transformations in human plasma. ${ }^{90}$ However, the application of time-resolved ICP-MS for NP-cell interaction is still in its infancy.

\subsubsection{Analysis of cell-associated nanoparticles at single cell level}

Laser ablation ICP-MS and laser desorption/ionization mass spectrometry

In addition to quantitative MS-based methods introduced above, which allow the quantitative measurement of nanoparticles and their constituent elements in solutions, methods that allow similar analysis to be performed on surfaces have also been developed. Here, two such methods: laser desorption/ionization mass spectrometry (LDI-MS) and laser ablation inductively coupled plasma mass spectrometry (LA ICP-MS) are discussed.

In LA-ICP-MS, also referred to as "chemical imaging" (see reviews by Becker et al. ${ }^{91}$ and Pozebon et al. ${ }^{92}$ ), a pulsed laser beam is used to ablate (eject) small quantities of material from the solid surface of a sample, enclosed in a chamber filled with inert gas. Ablated aerosol is then transported, with the stream of carrier gas, to an ICP-MS instrument for elemental and/or isotopic analysis. LA-ICP-MS requires little or no sample preparation, offers good sample throughput and in optimal conditions sample resolution $<1 \mu \mathrm{m}$. This resolution can be achieved through the use of a narrow beam diameter and low laser rastering rate, but at the expense of analyses time and sensitivity. Still, the micron-range resolution is not enough for the detection of nanoparticles and for nano-range resolution additional methodological advances are to be expected. Examples of studies where LA-ICP-MS has been used to asses cell-nanoparticle interactions include Böhme et al. ${ }^{93}$ who applied LA-ICP-MS to study metallic nanoparticles in crustaceans and zebrafish embryos and Managh et al. ${ }^{94}$ who demonstrated the applicability of LA-ICP-MS for the analysis of single human macrophages exposed to $50 \mathrm{~nm}$ Au particles.

LDI-MS works essentially similarly to LA-ICP-MS - the sample is irradiated with a laser beam and subsequently, mass spectrometry analysis is performed. This method has been used to analyze and image carbon ${ }^{95}$ and $\mathrm{Au}$ nanoparticles ${ }^{96,97}$ in animal tissues. In addition to being relatively sensitive (e.g., $50 \mathrm{nM}$ for Au nanoparticles), LA-ICP-MS enables the identification of surface ligands of nanoparticles thus creating a specific "barcode" for each nanoparticle. ${ }^{97}$ In more advanced settings, LDI-MS has been used to quantify cell surface bound and internalized nanoparticles. ${ }^{98}$ In this case, laser fluency absorption, which can be tuned to desorb and then ionize monolayers of nanoparticles outside of intact cells, is performed. By using the optimized set-up, the authors 
demonstrated that after $1 \mathrm{~h}$ exposure, $>50 \%$ of Au NPs in human hepatocellular carcinoma HepG2 cells were bound to cell surface.$^{98}$ Similar results were obtained also for chinese hamster ovary cells in which case the authors demonstrated time dependent uptake of Au NPs. While after 15 min exposure of cell to Au NPs in vitro, cellular uptake was negligible and almost all particles were bound to the cell surface. By 30 min exposure, the proportion of intracellular Au NPs had increased and after $60 \mathrm{~min}$, the internal fraction of Au NPs made up about $50 \%$ of total cell-associated $\mathrm{Au}^{98}$

High-resolution secondary ion mass spectrometry (nanoSIMS)

SIMS, and in particular dynamic SIMS, offers high sensitivity and mass resolution coupled to spatial resolution that make the technique ideal to study nanoparticle interactions with tissues and cells at the subcellular level. Dynamic SIMS uses ion beam current to sputter away the surface of a sample ${ }^{99}$ and the secondary ions generated are then analyzed by a mass spectrometer to generate elemental (or isotopic) maps. As the sputtering process only removes a few atomic layers of the surface the elemental maps are not compromised by the sample interaction volume, as in the case for electron microscopy or X-ray fluorescence), and resolution in the order of few tens of nanometers can be achieved. While offering a great potential to investigate nanoparticle-cell interaction, nanoSIMS has a series of limitations that include the limited number of instruments available worldwide, difficulties in determining certain elements to obtain quantitative information, and strict sample preparation requirements. The latter two are the most problematic. Quantitation by nanoSIMS is complicated by the fact that the yields of secondary ions are different for the different ions and are influenced by the matrix, which is a serious challenge when working with biological materials where the matrix can substantially vary across subcellular compartments. ${ }^{100,101}$ As nanoSIMS operates under high vacuum, sample preparation requires dehydration and embedding to preserve cellular morphology. This must be achieved while preserving elemental distribution and it is a challenging step for biological samples. Despite these limitations, nanoSIMS is a very promising technique to assess nanoparticle distribution and has the additional advantage that surface morphological features can be observed at the same time via secondary electron images. Lopes et al. ${ }^{102}$ used nanoSIMS to assess the uptake and subcellular localization of $\mathrm{TiO}_{2}$ nanoparticles in human $\mathrm{HaCaT}$ keratinocytes and found that the nanoparticles were indeed taken up by the cells and were localized in the cytoplasm and on the nuclear membrane but were not present in the nucleus. Similarly, Georgantzopoulou et al. ${ }^{103}$ used nanoSIMS to assess the cellular localization of Ag nanoparticles in Caco-2 cells and found that they were localized in areas of high $\mathrm{P}$ and $\mathrm{S}$ content, which was attributed to the high affinity of $\mathrm{Ag}$ for these elements. An elegant application of nanoSIMS in nanomedicine is described by Proetto et al. ${ }^{104}$, who took full advantage of the isotopic capabilities of this technique to assess the cellular delivery of polymeric nanoparticles labelled with ${ }^{15} \mathrm{~N}$ and loaded with Pt. The results showed that Pt was succesfully delivered intracellularly by these nanoparticles by overlaying the distribution of Pt with the ${ }^{15} \mathrm{~N}$ enrichment distribution map.

Synchrotron based X-ray techniques for nanoparticle visualization in cells 
A number of synchrotron-based techniques are available for the visualization (and quantitation) nanoparticles interaction with cells. These include X-ray fluorescence microscopy (XFM) and tomography (XRF- $\mu \mathrm{CT}$ ), scanning and full-field transmission X-ray microscopy (STXM and TXM, respectively) and coherent diffraction imaging (CDI). These techniques make use of the tunability, high brilliance and coherence of modern synchrotron radiation sources, which, in combination with ever more advanced optics, can now allow resolution of objects at the nanometre scale. A comprehensive review of the various technique for nano-bio interface research was published by Wang et al. ${ }^{105}$

XFM and transmission techniques are based on the photo-electric effect: when an X-ray reaches a sample it will interact with all the elements in the sample having a binding energy of the core electrons below the energy of the incident X-ray. As a consequence, the X-ray will be absorbed and photoelectrons produced together with fluorescence that is characteristic for each element in the sample. In all cases, it is important to consider the penetrating characteristics of the X-rays used as this will dictate the thickness of the samples that can be analyzed in transmission as well as the interaction volume and spatial resolution of the various techniques along the path of the beam. Among these various techniques, 2D XFM mapping is arguably the most commonly used. This method is based on the focussing of an X-ray beam to a small spot size and the scanning of a sample through this focussed beam, with the consequent fluorescence emitted at each pixel deconvolved to obtain 2D maps of the area analyzed. Ferraro et al. ${ }^{106}$ used this technique, in combination with TEM and SEM, to assess the interaction of $\mathrm{CeO}_{2}$ nanoparticles with human HeLa cells, while Veronesi et al. ${ }^{107}$ visualized and quantified the distribution of ionic $\mathrm{Ag}$ and $\mathrm{Ag}$ nanoparticles in hepatocytes. Rashkow et al. ${ }^{108}$ used XFM to quantitatively detect the mass of $\mathrm{TiO}_{2}$ nanoparticles in human breast cancer cells and showed that nanoparticle concentration in individual cells in a population may differ by ca. 3-fold. It is important to note that in studies that use XFM the obtained maps visualizing cellassociated nanoparticles represent $2 \mathrm{D}$ compressions of $3 \mathrm{D}$ volumes and therefore this technique cannot be used to assess whether a nanoparticle is localized on the surface or inside a cell. To overcome this limitation James et al. ${ }^{109}$ collected a series of XFM elemental maps after repeated ablation cycles by focused ion-beam (FIB)-SEM. Using this method they were able to distinguish ZnO nanoparticles deposited on the surface of an individual human macrophage from those internalized. Another way to overcome the issues associated with the penetrating nature of $\mathrm{X}$-rays is fluorescence tomography, which, instead, takes advantage of this X-ray property $\left(\right.$ e.g. $\left.{ }^{110}\right)$. In this case, the sample is mapped in two dimensions at a number of angles and a 3D reconstruction of elemental distribution can be obtained. To our knowledge, this approach has not yet been used to assess nanoparticle distribution at subcellular level.

Transmission approaches in the 'water window' (284-543 eV) take advantage of the high absorption contrast between metallic nanoparticle and biological materials to enable visualization of nanoparticle distribution in cells. Using Transmission X-Ray Microscopy TXM Zhang et al. ${ }^{111}$ obtained a $3 \mathrm{D}$ visualization of $\mathrm{Au}$ and $\mathrm{TiO}_{2}$ nanoparticles in HeLa cells. Similarly, Wang et al. ${ }^{112}$ used full-field 
transmission tomography to assess the distribution of $\mathrm{Ag}$ nanoparticles in a single human monocyte and inferred toxicological pathways of Ag nanoparticles.

The advantage of above-discussed synchrotron techniques is that sample preparation can be minimized and all these techniques can be performed on frozen-hydrated samples. Furthermore, as discussed below, the various visualization techniques discussed here can be coupled, often in the same experiment, with speciation techniques available at the same synchrotron beamline. The spatial resolution capability of these techniques is also improving thanks to the development of more sophisticated optics and beamline components and the coming online of new synchrotron sources based on multibend achromat lattice design that will provide unprecedented brilliance and coherence (e.g. $\left.{ }^{113}\right)$.

Single cell ICP-MS and mass cytometry (time of flight mass spectrometry)

While single particle ICP-MS discussed in 2.3.1. is gaining more and more popularity in characterization of nanoparticles, recent studies show that a similar approach can be successfully modified for the analysis of single cells (see ${ }^{84}$ for review). With this approach the cellular suspension can be conceptualized as a colloidal suspension and, considering its discrete nature, analyzed in time-resolved mode, obtaining signals which correspond to the mass of the element of interest associated with a single cell. If diluted suspension of single cells is introduced into the plasma, atomized and ionized, discrete clouds of ions originating from single cells, which are generally in the order of 300-500 $\mu \mathrm{s}$ in length, enter the detector individually. Finally, the numbers of one or more elemental ion species with specific mass-to-charge $(\mathrm{m} / \mathrm{z})$ ratios within each ion cloud, corresponding to an individual cell, can be quantified..$^{83,84,114}$ The feasibility of this approach has been demonstrated with bacterial, algal and mammalians cells. ${ }^{114-116}$ However, several challenges will need to be addressed prior to wide application of this methodology. The first challenge is inclusion of reliable calibration methods, as the ion plumes originated from the cell events may exhibit different behavior compared to single ion standard suspensions used for calibration. The second challenge is the optimization of transport efficiency of the sample which in current settings is typically low (6$10 \%)$. Additional issues include discarding of droplets carrying cells into the waste, ${ }^{117}$ and incomplete atomization and ionization of the cells in the plasma. These issues are at least partly overcome in an instrument that is also based on the introduction of single cells to plasma but in which the detection is carried out in time of flight mass spectrometry (TOF-MS) mode. Despite lower sensitivity, TOF-MS instruments are capable of much faster throughput and feature a simultaneous detection of multiple isotopes and ions, in contrast to the sequential detection of isotopes performed by the mass filter systems. Typical dwell times for TOF-MS instruments in the order of 10-30 $\mu$ s allow more accurate resolution of individual ion clouds and, subsequently, faster sample acquisition. ${ }^{75,118}$ The generic name for this approach, when used to investigate cells, has been termed Mass Cytometry (MC) (Figure 7). ${ }^{118}$ As mentioned above, TOF-MS instruments are capable of scanning broad regions of the $\mathrm{m} / \mathrm{z}$ spectrum in a quasi-simultaneous manner, and thus, detecting several elements in the same sample. This feature has led to it being embraced by researchers in the fields of immunology and cell 
biology where it is most often used to perform immunophenotyping where a heterogeneous mixture of cells is incubated with antibodies that have been labelled e.g., with stable isotopes of lanthanides. ${ }^{119}$ To date, most studies involving MC and nanoparticles have done so with a view to use the particles as labels for specific probes. For example, Bendall et al. ${ }^{120}$ used quantum dots as a mass label on antibodies, Schulz et al. ${ }^{121}$ used metallic Ag, and Lin et al. and Tong et al. used lanthanide ${ }^{122,123}$ nanospheres as effective probes for antibodies. Investigation of the interaction of NPs with cells in culture and from in vivo samples are obvious applications for the technique. In a recent study Yang et al. used the multiparameter immunophenotyping capabilities of $\mathrm{MC}$ to investigate the association of Au NPs with cell mixtures in in-vivo mouse models. ${ }^{124}$ After administration of Au NPs to mice, single cell suspensions were prepared from the target organs that were analyzed for their Au content as well as identified using nine different antibodies. The authors showed that subcutaneously injected Au particles were taken up selectively by specific immune-cell subsets - and this information was used to design a nanoparticle-based vaccine strategy. ${ }^{124}$

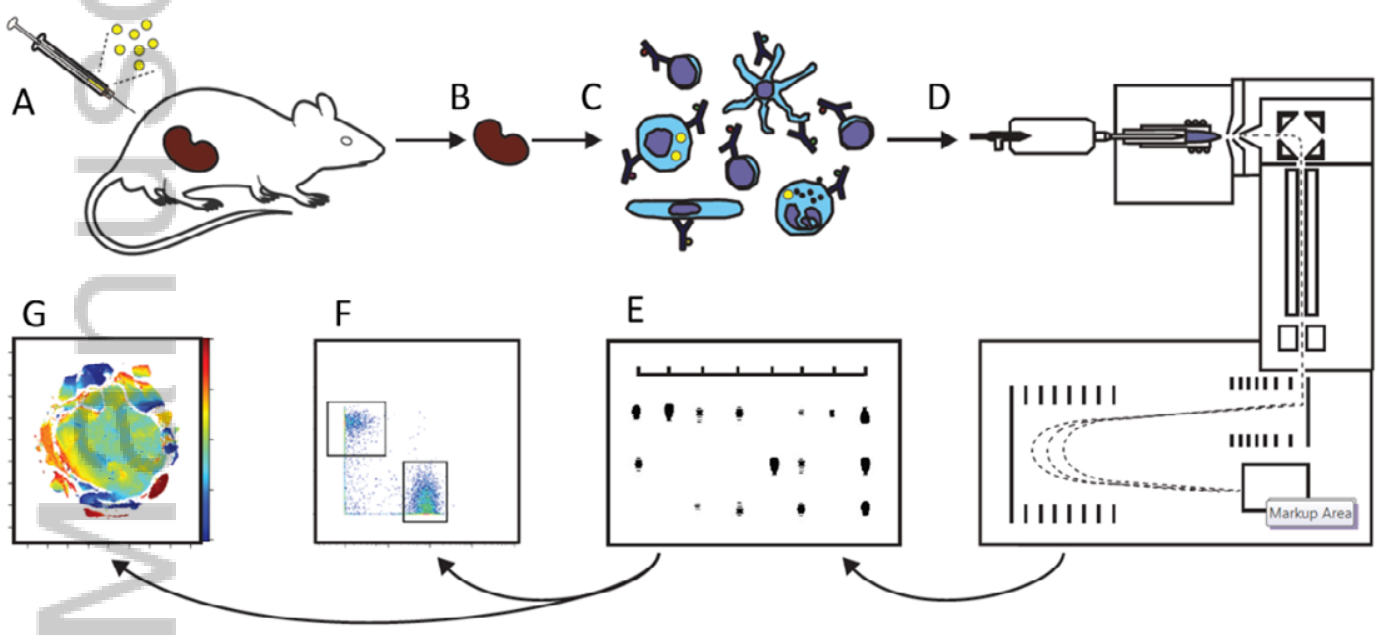

Figure 7. Workflow of in vivo nanoparticle/cell interaction analysis using mass cytometry. (A) nanoparticles are administered to experimental animal, (B) tissue from animal is isolated, (C) single cell suspension is prepared from tissue and stained with metal-labelled probes, including antibodies, (D) single cell suspension is analyzed by mass cytometry, $(E)$ output of mass cytometer is converted to Flow Cytometry Standard file, which allows either (F) manual or (G) machine-learning based analysis of nanoparticle uptake by individual cells.

\section{Methods to distinguish between cell surface bound and internalized nanoparticles}

Although the importance of cellular localization of nanoparticles on therapeutic or toxic effects is well acknowledged, assessment of cellular localization is a challenging task and, as seen from Table 1 , can be accomplished only by microscopy methods that are either very low throughput or lack necessary resolution for nanoparticles. As discussed in chapter 2.2.3, certain conclusions on cellular 
localization of nanoparticles can be also made based on flow cytometry side scatter signals. In addition to direct visualization methods such as microscopy, cellular localization of nanoparticles can be determined by using a combination of chemicals that selectively release cell surface bound nanoparticles and retain only intracellular particle fraction. In following sections, the advantages and disadvantages of these methods are discussed.

\subsection{Microscopy methods}

The most common techniques employed for identifying intracellular nanoparticles are confocal fluorescence microscopy and TEM. As discussed above, TEM with sequential preparation of ultrathin slices of a specimen can even be used to reconstruct 3D images and subsequently determine the cellular localization of nanoparticles ${ }^{54,53}$. In addition to TEM techniques, field emission (FE) SEM has been used to distinguish between nanoparticles within cells or on the external surface of cells. This method has an advantage of reducing the sample preparation steps and thus, preparation time, and allows resolution up to $1 \mathrm{~nm}^{125}$. Surface bound and intracellular nanoparticles can be distinguished by using different accelerator voltages as demonstrated by James et al. ${ }^{126}$. Thus, coupled with energy dispersive X-ray (EDX) analysis, and backscattered electron imaging FE-SEM offers an ideal analytical platform for the characterization of nanoparticles in and on the cells ${ }^{127,128}$. Finally, the pioneering work of Havrdova et al. ${ }^{129}$ demonstrated that FE-SEM can be used to determine the cellular ultrastructural localization of nanoparticles (Figure 8).

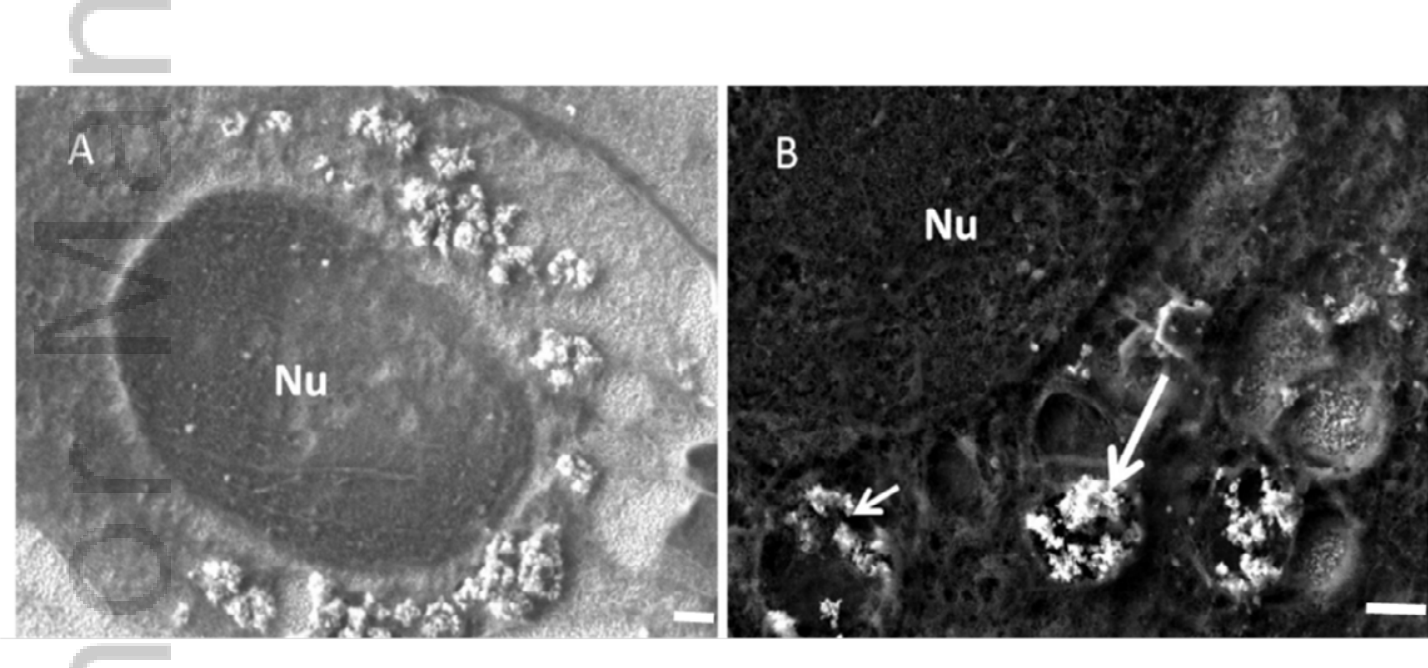

Figure 8. Localization of superparamagnetic iron oxide nanoparticles in the endosomes of cells. (A) vesicles around nucleus (Nu), 4300x magnification; (B) detailed view of endosomes near nucleus, $8000 x$ magnification. White arrow indicates the localization of endosomal nanoparticles. Scale bar: 1 $\mu \mathrm{m}$. From Havrdova et al. ${ }^{129}$ Copyright (c) 2014 Elsevier Ltd. All rights reserved.

\subsection{Chemical etching methods}


Chemical etching, i.e. the use of a chemical or a combination of chemicals, to remove cell surface bound nanoparticles, has been applied in several studies as a method to assess cellular localization of nanoparticles. Although the concept may sound straightforward, due to the different properties of each nanoparticle the practical application of this approach is particle-specific and also depends on the used cell type. Chemical etching is usually applied to living cells and one of the important requirements of these methodologies is their low cytotoxicity.

In 2009, Cho et al. ${ }^{130}$ introduced an etching method that enables the removal of $\mathrm{Au}$ nanoparticles from cells. This method was optimized using human adenocarcinoma cell line SK-BR-3 and used a combination of iodine $\left(\mathrm{I}_{2}\right)$ and potassium iodide $(\mathrm{KI})$ as etchant. This chemical mixture was selected after the authors had tried a recipe involving $0.1 \%$ Tween 20, trypsin, and diluted aqua regia in removal of extracellular Au nanoparticles, and after optimization, $0.34 \mathrm{mM} \mathrm{I}_{2}$ and $2 \mathrm{mM} \mathrm{KI}$ and 5 min etching time was chosen. These conditions efficiently dissolved 10000 Au nanospheres which was theoretically less than what was bound to cell surfaces. The authors showed that only a minor fraction of polyvinyl alcohol functionalized Au nanoparticles attached to cell surfaces, a small fraction of citrate-functionalized Au particles were cell surface bound but significantly more polyallylamine hydrochloride functionalized $\mathrm{Au}$ nanoparticles were surface attached ${ }^{130}$ and that among antibody-functionalized $\mathrm{Au}$ nanospheres and nanocubes, attachment of the cubical structures to cell surfaces was more pronounced ${ }^{131}$. Although the described $\mathrm{I}_{2} / \mathrm{KI}$ methodology proved effective for cell surface removal of Au nanoparticles, its efficacy in dissolving nanoparticles with different composition has not been studied.

A different chemical etching protocol has been described for Ag nanoparticles by Braun et al. ${ }^{68}$. These authors used a mixture of hexacyanoferrate $\left(\mathrm{Fe}(\mathrm{III})(\mathrm{CN})_{6}\right)$ that oxidizes metallic $\mathrm{Ag}$ (in nanoparticle form) to $\mathrm{Ag}$ ions, and thiosulphate $\mathrm{S}_{2} \mathrm{O}_{3}$ which ligates and clears away the formed $\mathrm{Ag}$ ions. The reagents do not penetrate the cell membrane ${ }^{132}$, thus leaving intracellular Ag nanoparticles protected from dissolution (Figure 9). The optimization of etchant concentration and time showed that the etching time depended on etchant concentration and was $1 \mathrm{~min}$ for $0.25 \mathrm{mM} \mathrm{K}{ }_{3} \mathrm{Fe}(\mathrm{CN})_{6}$ and $\mathrm{Na}_{2} \mathrm{~S}_{2} \mathrm{O}_{3} * 5 \mathrm{H}_{2} \mathrm{O}$ mixture and less than $10 \mathrm{~s}$ in the case of a $2 \mathrm{mM} \mathrm{Na}_{2} \mathrm{~S}_{2} \mathrm{O}_{3} * 5 \mathrm{H}_{2} \mathrm{O}$ mixture. The developed etching method has also been used by other authors. For example, Ivask et al. used this approach to remove Ag nanoparticles from human T-cells ${ }^{30}$ and similarly to Cho et al. ${ }^{131}$ found that nanoparticles with positive surface charge bound to cell surface to a greater extent than particles with negative surface charge. 

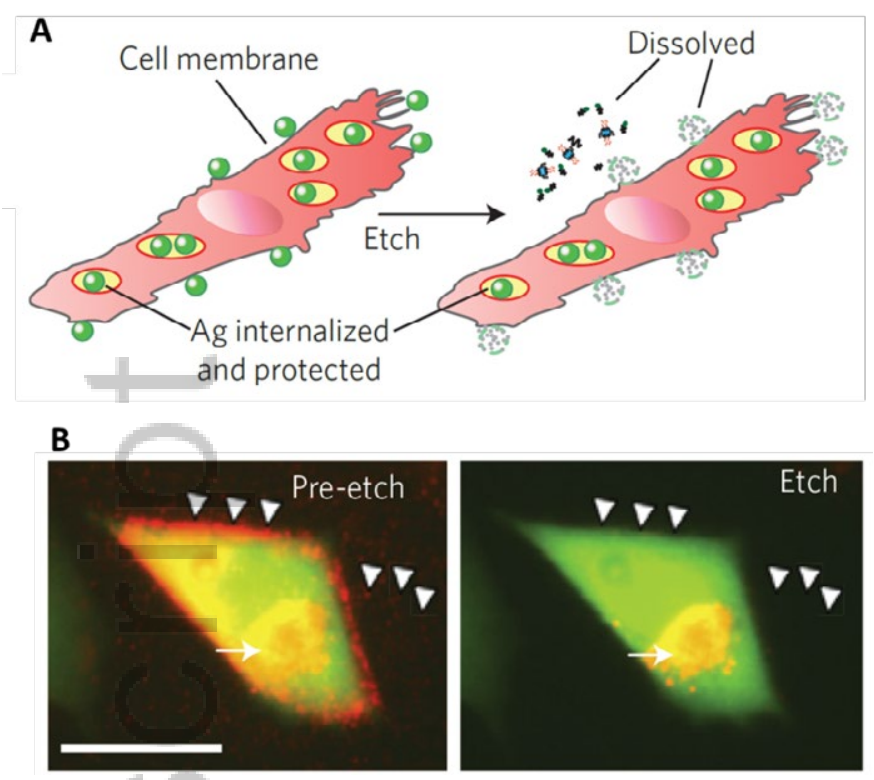

Figure 9. Removal of cell surface bound Ag nanoparticles by hexacyanoferrate-thiosulphate redoxbased etchant. A: schematic of Ag nanoparticle removal from cell surface; B: fluorescence microscopy visualization of $\mathrm{Ag}$ nanoparticle removal from cell surface. Ag nanoparticles were labelled with red fluorophore. In pre-etching conditions, clear binding of Ag NPs to cell surface can be seen while after etching, only intracellular vesicular structures carrying fluorescent $\mathrm{Ag}$ nanoparticles can be observed. Figure is modified from Braun et al. ${ }^{68}$ C 2014, Rights Managed by Nature Publishing Group.

\section{Methods and approaches to assess cellular speciation of nanoparticles}

In addition to the extent of cellular interaction and (intra)cellular localization, the cellular effects of nanoparticles are determined by various transformations that may take place with those particles during the test. ${ }^{133}$ As shown in Table 1, while certain knowledge on nanoparticle transformation can be obtained by microscopy methods (change in nanoparticle shape, size, hyperspectral properties), only synchrotron methods that are introduced in next section are truly capable of such analysis.

\subsection{Synchrotron methods}

Synchrotron X-ray absorption spectroscopy (XAS), which uses the ability to tune the energy of incident $X$-rays at synchrotrons to obtain information regarding the oxidation state, symmetry and identity of the coordinating ligand environment for an element of interest, is one of the few methods capable for elemental speciation analysis. As the energy of an incident X-ray is progressively increased, a point is reached where the energy of the X-ray approximates the binding energy of core level electrons for the element on interest. At this point a sharp, step-like increase in $\mathrm{X}$-ray absorption occurs (this feature is called the absorption edge) due to a core electron that is ejected from the atom into the continuum (i.e. photoelectron). As the incident energy is further 
increased, the kinetic energy of the photoelectron increases and cause it to scatter off neighboring atoms. This series of processes give rise to XAS spectra from which speciation information (e.g. oxidation and binding environment) can be obtained.

XAS can be applied to assess the average chemical speciation of an element of interest in a pellet of cells ('bulk' speciation) or, using focused beams, at a specific point in space (with the limitations previously discussed regarding the penetrating nature of X-rays). Also, this technique can be coupled with chemical etching approaches described above to gain information on the speciation of adsorbed versus internalized element. It should be pointed out that with XAS it is the chemical nature rather than the physical form that is assessed. For instance, the XAS spectrum of a metallic nanoparticle is often very similar and indistinguishable from the spectrum of a bulk counterpart. The main advantage of this technique is that it does not require any pre-treatment of samples or extraction/isolation of the nanoparticles as it can be conducted in situ or even in vivo on hydrated cells (even though cryo conditions are often used to reduce the risks of artefacts caused by the intensity of the X-ray beam).

A review describing the potential of synchrotron XAS methods in metal speciation analysis has been published by Gräfe et al. ${ }^{134}$ An example of 'bulk' XAS speciation of nanoparticle interaction with cells was recently presented by Ivask et al. ${ }^{135}$ who assessed the chemical forms of $\mathrm{Cu}$ and $\mathrm{Zn}$ in cells exposed to the respective oxide nanoparticles. Using this technique it was demonstrated that both these nanoparticles completely transformed (e.g. dissolved and $\mathrm{Zn}$ and $\mathrm{Cu}$ redistributed) in the culture medium and, as a result, the speciation of $\mathrm{Cu}$ and $\mathrm{Zn}$ in nanoparticle exposed cells was identical to that of cells exposed to their ionic counterparts. An elegant study utilising both 'bulk' and laterally resolved XAS to assess the speciation of $\mathrm{Ce}$ in cells exposed to $\mathrm{CeO}_{2}$ was recently published by Ferraro et al. ${ }^{106}$. The bulk analysis indicated a partial reduction of Ce in cells exposed for 24 hours to the nanoparticles. The laterally resolved techniques showed that in regions with high $\mathrm{Ce}$ concentration $\mathrm{Ce}$ (IV) was dominant which was interpreted as nanoparticles in endolysosomes. In contrast, $\mathrm{Ce}$ (III) was more prevalent in regions with a lower total Ce content.

As in the case for synchrotron-based imaging techniques, advantages in beamline instrumentation, sample environments and synchrotron source is destined to further enhance the capabilities of these techniques.

\section{Conclusions}

With increasing use of nanoscale materials in various industrial and biomedical applications, reliable assessment of cell-associated nanoparticles is becoming ever more important. The extent and mode of cellular association drives the physiological effects of nanoparticles. In turn, the nature of this association can determine the efficacy of medically relevant nanoparticles, or alternatively, adverse effects of potentially toxic nanoscale materials. Thus, by understanding the parameters that affect this interaction, one can modulate the properties of nanoparticles to attain specific and tunable cellular interactions and/or mitigate their negative effects. 
With the requirement for reliable analysis of cell-associated nanoparticles established, the question of how best to achieve it comes into focus. The analysis of nanoparticles in a given sample aims to address: detection (are nanoparticles present?), chemical identification (what type of nanoparticles is present?), quantitation (how many nanoparticles are in the sample?), characterization (size, shape, surface properties and aggregation state of the nanoparticles) and localization (in which cellular compartment are nanoparticles present?), also considering the alterations that the nanoparticles undergo when in contact with biological entities. The combination of these quests may seem to indicate that assessing the nanoparticle-cell interactions is a task made almost impossible by immense complexity of the investigated system. Adding complexity to an already complex matter, the list of available analytical methods goes on and on, and sorting through the advantages and drawbacks of each approach may represent a challenge itself. Clearly, analytical approaches need to be tailored to address specific hypotheses in a given sample type for a given material, paying special attention to the generation of artefacts, and focusing on the primary underlying research questions.

Although extremely useful for "proving" that the nanoparticles are associated with the cells, widely utilized light (and fluorescence light) microscopy-based methods usually lack sub-micron resolution necessary for the visualization of single nanoparticles (sized $<100 \mathrm{~nm}$ by definition). The excellent $\sim 0.1 \mathrm{~nm}$ resolution achievable with electron microscopy is opposed by tedious sample preparation requirements and extremely low sample throughput. In addition, due its merely qualitative analytical capabilities, microscopy hardly allows collection of statistically relevant data, even less so quantitation of nanoparticles. Analytical spectrometry-based methods (e.g., mass spectrometry, MS), on the other hand, enable the quantitative analysis of nanoparticles but are only applicable for metal-containing particulates. MS-based methods such as single particle (and single cell) inductively coupled plasma (ICP) MS, single cell time of flight MS (mass cytometry), laser ablation MS and laser desorption/ionization MS, developed in recent years, are very well-suited to analyze metalcontaining nanoparticles at single cell level. Although very promising for the analysis of nanoparticlecell interactions, these methods are limited to measuring the constituent elements of nanoparticles and do not provide any information regarding intactness or elemental speciation of nanoparticles in cellular environment. The most appropriate methods for studying chemical transformations of nanoparticles upon their interactions with biological entities and cellular uptake seem to be synchrotron-based methods. X-ray absorption near edge structure method enables the analysis of different species of the analyzed element (e.g., metal constituents of a nanoparticle) in the samples. Finally, none of the described methods is able to quantitatively analyze cellular localization of nanoparticles (e.g., separation of intracellular and extracellular nanoparticles). With that purpose, specific strategies such as chemical etching where e.g., cell surface-bound nanoparticles are selectively removed can be applied.

The merits of various qualitative, semi-quantitative and quantitative methods have been discussed endlessly, and the technological advances continuously propel the analytics towards faster, highly sensitive and selective detection and characterization of nanoscale materials. Established that there 
is no single analytical methodology capable to provide all the required information, multiple techniques should be applied. The studies addressing the nanoparticle-cell interactions have become increasingly holistic and have grown in sophistication to approach the complexity of nanoparticle behaviour combined with the complexity of biological systems. Generally, light scattering/ electronic microscopy imaging, element-specific techniques, nano-specific size fractionation methodologies, and particle counting techniques can be mixed and matched in the multimodal approach. The use of multiple techniques that provide multiple lines of analytical evidence and statistically sound information in terms of nanoparticle characterization and localization is undoubtedly a promising strategy for advancing our knowledge in the field of nanoparticle-cell interactions.

\section{Acknowledgments}

This work was supported by Estonian Research Council grant PUT748 and European Regional Development Fund project TK134 and SA Government PRIF grant "International Research Cluster for Nanosafety". This work was performed in part at the Materials Characterisation and Fabrication Platform (MCFP) at the University of Melbourne and the Victorian Node of the Australian National Fabrication Facility (ANFF).

\section{References}

1. Doane TL, Burda C. The unique role of nanoparticles in nanomedicine: imaging, drug delivery and therapy. Chem Soc Rev 2012, 41: 2885-2911.

2. Shang L, Nienhaus K, Nienhaus GU. Engineered nanoparticles interacting with cells: size matters. J Nanobiotechnol 2014, 12: 5.

3. Morteza Hasanzadeh K, Frances JH, Nicolas HV. Insights into Cellular Uptake of Nanoparticles. Curr Drug Deliv 2015, 12: 63-77.

4. Mu Q, Jiang G, Chen L, Zhou H, Fourches D, Tropsha A, Yan B. Chemical Basis of Interactions Between Engineered Nanoparticles and Biological Systems. Chem Rev 2014, 114(15): 7740-7781.

5. Nel AE, Madler L, Velegol D, Xia T, Hoek EMV, Somasundaran P, Klaessig F, Castranova V, Thompson M. Understanding biophysicochemical interactions at the nano-bio interface. Nat Mater 2009, 8: 543-557.

6. Lynch I, Feitshans IL, Kendall M. 'Bio-nano interactions: new tools, insights and impacts': summary of the Royal Society discussion meeting. Philos Trans R Soc Lond B Biol Sci 2015, 370: 20140162.

7. Vanhecke D, Rodriguez-Lorenzo L, Clift MJ, Blank F, Petri-Fink A, Rothen-Rutishauser B. Quantification of nanoparticles at the single-cell level: an overview about state-of-the-art techniques and their limitations. Nanomedicine (Lond) 2014, 9(12):1885-900.

8. Collins AR, Annangi B, Rubio L, Marcos R, Dorn M, Merker C, Estrela-Lopis I, Cimpan MR, Ibrahim M, Cimpan E, Ostermann M, Sauter A, Yamani NE, Shaposhnikov S, Chevillard S, Paget V, Grall R, Delic J, de-Cerio FG, Suarez-Merino B, Fessard V, Hogeveen KN, Fjellsb $\varnothing$ LM, Pran ER, Brzicova T, Topinka J, Silva MJ, Leite PE, Ribeiro AR, Granjeiro JM, Grafström R, Prina-Mello A, Dusinska M. High throughput toxicity screening and intracellular detection of nanomaterials. Wiley Interdiscip Rev Nanomed Nanobiotechnol 2017, 9(1). 
9. Smith DJ. Ultimate resolution in the electron microscope? Mater Today 2008, 11, Supplement: $30-38$.

10. Combs CA. Fluorescence Microscopy: A Concise Guide to Current Imaging Methods. Curr Protocols Neurosci 2010, Unit2.1.

11. Salvati A, Åberg C, dos Santos T, Varela J, Pinto P, Lynch I, Dawson KA. Experimental and theoretical comparison of intracellular import of polymeric nanoparticles and small molecules: toward models of uptake kinetics. Nanomedicine: NBM 7: 818-826.

12. Yin Win K, Feng S-S. Effects of particle size and surface coating on cellular uptake of polymeric nanoparticles for oral delivery of anticancer drugs. Biomaterials 2005, 26: 2713-2722.

13. Elsaesser A, Taylor A, de Yanés GS, McKerr G, Kim E-M, O'Hare E, Howard CV. Quantification of nanoparticle uptake by cells using microscopical and analytical techniques. Nanomedicine 2010, 5: 1447-1457.

14. Dorney J, Bonnier F, Garcia A, Casey A, Chambers G, Byrne HJ. Identifying and localizing intracellular nanoparticles using Raman spectroscopy. Analyst 2012, 137: 1111-1119.

15. Wolfbeis OS. An overview of nanoparticles commonly used in fluorescent bioimaging. Chem Soc Rev 2015, 44: 4743-4768.

16. Oliveira E, Santos H M, Garcia-Pardo J, Diniz M, Lorenzo J, Rodriguez-Gonzalez B, Capelo J, Lodeiro C. Synthesis of functionalized fluorescent silver nanoparticles and their toxicological effect in aquatic environments (Goldfish) and HEPG2 cells. Front Chem 2013, 2013.00029

17. Mittal R, Bruchez MP. Calibration of Flow Cytometry for Quantitative Quantum Dot Measurements. Curr Protocols Neurosci 2009, Unit 6.26.

14. Dubertret B, Skourides P, Norris DJ, Noireaux V, Brivanlou AH, Libchaber A. In Vivo Imaging of Quantum Dots Encapsulated in Phospholipid Micelles. Science 2002, 298: 1759-1762.

19. Willig KI, Rizzoli SO, Westphal V, Jahn R, Hell SW. STED microscopy reveals that synaptotagmin remains clustered after synaptic vesicle exocytosis. Nature 2006, 440: 935-939.

20. Huang B, Babcock H, Zhuang X. Breaking the Diffraction Barrier: Super-Resolution Imaging of Cells. Cell 143: 1047-1058.

21. Zhuang X. Nano-imaging with STORM. Nat Photon 2009, 3: 365-367.

22. Rust MJ, Bates M, Zhuang X. Sub-diffraction-limit imaging by stochastic optical reconstruction microscopy (STORM). Nat Meth 2006, 3: 793-796.

23. Allen JR, Ross ST, Davidson MW. Structured Illumination Microscopy for Superresolution. Chem Phys Chem 2014, 15: 566-576.

24. Dyba M, Jakobs S, Hell SW. Immunofluorescence stimulated emission depletion microscopy. Nat Biotech 2003, 21: 1303-1304.

25. Müller T, Schumann C, Kraegeloh A. STED Microscopy and its Applications: New Insights into Cellular Processes on the Nanoscale. Chem Phys Chem 2012, 13: 1986-2000.

26. Huang B, Bates M, Zhuang X. Super resolution fluorescence microscopy. Annu Rev Biochem 2009, 78: 993-1016.

27. Schmidt R, Wurm CA, Punge A, Egner A, Jakobs S, Hell SW. Mitochondrial Cristae Revealed with Focused Light. Nano Lett 2009, 9: 2508-2510.

28. Schermelleh L, Carlton PM, Haase S, Shao L, Winoto L, Kner P, Burke B, Cardoso MC, Agard DA, Gustafsson MGL, Leonhardt H, Sedat JW. Subdiffraction Multicolor Imaging of the Nuclear Periphery with 3D Structured Illumination Microscopy. Science 2008, 320: 1332-1336. 
29. Hu M, Novo C, Funston A, Wang H, Staleva H, Zou S, Mulvaney P, Xia Y, Hartland GV. Darkfield microscopy studies of single metal nanoparticles: understanding the factors that influence the linewidth of the localized surface plasmon resonance. J Mat Chem 2008, 18: 1949-1960.

30. Ivask A, Visnapuu M, Vallotton P, Marzouk ER, Lombi E, Voelcker NH. Quantitative multimodal analyses of silver nanoparticle-cell interactions: Implications for cytotoxicity. Nanolmpact 2016, 1: 29-38.

31. Vallotton P, Angel B, McCall M, Osmond M, Kirby J. Imaging nanoparticle-algae interactions in three dimensions using Cytoviva microscopy. J Microsc 2015, 257: 166-169.

32. Malysheva A, Voelcker N, Holm PE, Lombi E. Unraveling the Complex Behavior of AgNPs Driving NP-Cell Interactions and Toxicity to Algal Cells. Env Sci Technol 2016, 50: 12455-12463. 33. Weinkauf H, Brehm-Stecher BF. Enhanced dark field microscopy for rapid artifact-free detection of nanoparticle binding to Candida albicans cells and hyphae. Biotechnol J 2009, 4: 871879.

34. Gibbs-Flournoy EA, Bromberg PA, Hofer TP, Samet JM, Zucker RM. Darkfield-Confocal Microscopy detection of nanoscale particle internalization by human lung cells. Part Fibre Toxicol 2011, 8: 2.

35. Anderson DS, Patchin ES, Silva RM, Uyeminami DL, Sharmah A, Guo T, Das GK, Brown JM, Shannahan J, Gordon T, Chen LC, Pinkerton KE, Van Winkle LS. Influence of particle size on persistence and clearance of aerosolized silver nanoparticles in the rat lung. Toxicol Sci 2015, 144(2):366-81.

36. Roth GA, del Pilar Sosa Peña M, Neu-Baker NM, Tahiliani S, Brenner SA. Identification of metal oxide nanoparticles in histological samples by enhanced darkfield microscopy and hyperspectral mapping. J Vis Exp 2015, (106): 53317.

37. Klein ND, Hurley KR, Feng ZV, Haynes CL. Dark Field Transmission Electron Microscopy as a Tool for Identifying Inorganic Nanoparticles in Biological Matrices. Anal Chem 2015, 87: 4356-4362.

38. Roth GA, Tahiliani S, Neu-Baker NM, Brenner SA. Hyperspectral microscopy as an analytical tool for nanomaterials. Wiley Interdiscip Rev Nanomed Nanobiotechnol 2015, 7: 565-579.

39. Peña MDPS, Gottipati A, Tahiliani S, Neu-Baker NM, Frame MD, Friedman AJ, Brenner SA. Hyperspectral imaging of nanoparticles in biological samples: Simultaneous visualization and elemental identification. Microsc Res Tech 2016, 79: 349-358.

40. Stacy BM, Comfort KK, Comfort DA, Hussain SM. In Vitro Identification of Gold Nanorods through Hyperspectral Imaging. Plasmonics 2013, 8: 1235-1240.

41. Pratsinis A, Hervella P, Leroux J-C, Pratsinis SE, Sotiriou GA. Toxicity of Silver Nanoparticles in Macrophages. Small 2013, 9: 2576-2584.

42. Leclerc S, Wilkinson KJ. Bioaccumulation of Nanosilver by Chlamydomonas reinhardtiiNanoparticle or the Free Ion? Env Sci Technol 2014, 48: 358-364.

43. Vishnupriya S, Chaudhari K, Jagannathan R, Pradeep T. Single-Cell Investigations of Silver Nanoparticle-Bacteria Interactions. Part Part Syst Charact 2013, 30: 1056-1062.

44. Chen AL, Hu YS, Jackson MA, Lin AY, Young JK, Langsner RJ, Drezek RA. Quantifying spectral changes experienced by plasmonic nanoparticles in a cellular environment to inform biomedical nanoparticle design. Nanoscale Res Lett 2014, 9: 454-454.

45. Grabinski C, Schlager J, Hussain S. Hyperspectral Microscopy for Characterization of Gold Nanoparticles in Biological Media and Cells for Toxicity Assessment. In Nanomaterial Interfaces in Biology: Methods and Protocols,. ergese P, Hamad-Schifferli K, Eds. Humana Press: Totowa, NJ, 2013; pp 167-178. 
46. Herdson PB. The LAB: General Principles of Electron Microscopy. Hospital Topics 1968, 46: 79-82.

47. Schrand AM, Schlager JJ, Dai L, Hussain SM. Preparation of cells for assessing ultrastructural localization of nanoparticles with transmission electron microscopy. Nat Protocols 2010, 5: 744-757. 48. Weston AE, Armer HEJ, Collinson LM. Towards native-state imaging in biological context in the electron microscope. J Chem Biol 2010, 3: 101-112.

49. Fischer ER, Hansen BT, Nair V, Hoyt FH, Dorward DW. Scanning Electron Microscopy. Curr Prot Microbiol 2012, Unit2B.2.

50. Elsaesser A, Barnes CA, McKerr G, Salvati A, Lynch I, Dawson KA, Howard CV. Quantification of nanoparticle uptake by cells using an unbiased sampling method and electron microscopy. Nanomedicine (Lond) 2011, 6(7):1189-98

51. Peckys DB, de Jonge N. Visualizing Gold Nanoparticle Uptake in Live Cells with Liquid Scanning Transmission Electron Microscopy. Nano Lett 2011, 11: 1733-1738.

52. Donald AM. The use of environmental scanning electron microscopy for imaging wet and insulating materials. Nat Mater 2003, 2: 511-516.

53. Summers HD, Brown MR, Holton MD, Tonkin JA, Hondow N, Brown AP, Brydson R, Rees P. Quantification of Nanoparticle Dose and Vesicular Inheritance in Proliferating Cells. ACS Nano 2013, 7: 6129-6137.

54. Hondow N, Brown A, Summers HD, Brown MR, Rees P, Holton MD, Brydson R. Quantifying Nanoparticle-Cell Interactions. Microsc Microanal 2014, 20 1300-1301.

55. Schie IW, Huser T. Methods and Applications of Raman Microspectroscopy to Single-Cell Analysis. Appl Spectrosc 2013, 67: 813-828.

56. Smith R, Wright KL, Ashton L. Raman spectroscopy: an evolving technique for live cell studies. Analyst 2016, 141: 3590-3600.

57. Wang Y, Irudayaraj J. Surface-enhanced Raman spectroscopy at single-molecule scale and its implications in biology. Philos Trans R Soc Lond B Biol Sci 2013, 368: 20120026.

58. Zhang C, Zhang D, Cheng J-X. Coherent Raman Scattering Microscopy in Biology and Medicine. Annu Rev Biomed Eng 2015, 17: 415-445.

59. Taylor J, Huefner A, Li L, Wingfield J, Mahajan S. Nanoparticles and intracellular applications of surface-enhanced Raman spectroscopy. Analyst 2016, 141: 5037-5055.

60. Kneipp K, Haka AS, Kneipp H, Badizadegan K, Yoshizawa N, Boone C, Shafer-Peltier KE, Motz JT, Dasari RR, Feld MS. Surface-Enhanced Raman Spectroscopy in Single Living Cells Using Gold Nanoparticles. Appl Spectrosc 2002, 56: 150-154.

61. Kneipp J, Kneipp H, McLaughlin M, Brown D, Kneipp K. In Vivo Molecular Probing of Cellular Compartments with Gold Nanoparticles and Nanoaggregates. Nano Lett 2006, 6: 2225-2231.

62. Adan A, Alizada G, Kiraz Y, Baran Y, Nalbant A. Flow cytometry: basic principles and applications. Crit Rev Biotechnol 2017, 37: 163-176.

63. Smith RA, Giorgio TD. Quantitative measurement of multifunctional quantum dot binding to cellular targets using flow cytometry. Cytometry A 2009, 75A: 465-474.

64. Zucker RM, Massaro EJ, Sanders KM, Degn LL, Boyes WK. Detection of $\mathrm{TiO}_{2}$ nanoparticles in cells by flow cytometry. Cytometry A 2010, 77A: 677-685.

65. Choi SY, Yang N, Jeon SK, Yoon TH. Semi-Quantitative Estimation of Cellular $\mathrm{SiO}_{2}$ Nanoparticles Using Flow Cytometry Combined with X-ray Fluorescence Measurements. Cytometry A 2014, 85: 771-780. 
66. Marangon I, Boggetto N, Ménard-Moyon C, Venturelli E, Béoutis M-L, Péchoux C, Luciani N, Wilhelm C, Bianco A, Gazeau F. Intercellular Carbon Nanotube Translocation Assessed by Flow Cytometry Imaging. Nano Lett 2012, 12: 4830-4837.

67. Suzuki H, Toyooka T, Ibuki Y. Simple and Easy Method to Evaluate Uptake Potential of Nanoparticles in Mammalian Cells Using a Flow Cytometric Light Scatter Analysis. Environ Sci Technol 2007, 41: 3018-3024.

68. Braun GB, Friman T, Pang H-B, Pallaoro A, de Mendoza TH, Willmore A-MA, Kotamraju VR, Mann AP, She Z-G, Sugahara KN, Reich NO, Teesalu T, Ruoslahti E. Etchable Plasmonic Nanoparticle Probes to Image and Quantify Cellular Internalization. Nat Mater 2014, 13: 904-911.

69. Schmid O, Stoeger T. Surface area is the biologically most effective dose metric for acute nanoparticle toxicity in the lung. J Aerosol Sci 2016, 99: 133-143.

70. Teeguarden JG, Hinderliter PM, Orr G, Thrall BD, Pounds JG. Particokinetics In Vitro:

Dosimetry Considerations for In Vitro Nanoparticle Toxicity Assessments. Toxicol Sci 2007, 95: 300312.

71. Cohen JM, Teeguarden JG, Demokritou P. An integrated approach for the in vitro dosimetry of engineered nanomaterials. Part Fibre Toxicol 2014, 11: 20-20.

72. Wittmaack K. In Search of the Most Relevant Parameter for Quantifying Lung Inflammatory Response to Nanoparticle Exposure: Particle Number, Surface Area, or What? Environ Health Persp 2007, 115: 187-194.

73. Chithrani BD, Chan WCW. Elucidating the Mechanism of Cellular Uptake and Removal of Protein-Coated Gold Nanoparticles of Different Sizes and Shapes. Nano Lett 2007, 7: 1542-1550.

74. Chithrani BD, Ghazani AA, Chan WCW. Determining the size and shape dependence of gold nanoparticle uptake into mammalian cells. Nano Lett 2006, 6.

75. Hendriks L, Gundlach-Graham A, Hattendorf B, Gunther D. Characterization of a new ICPTOFMS instrument with continuous and discrete introduction of solutions. J Anal At Spectrom 2017, 32: $548-561$.

76. Comi TJ, Do TD, Rubakhin SS, Sweedler JV. Categorizing Cells on the Basis of their Chemical Profiles: Progress in Single-Cell Mass Spectrometry. JACS 2017, 139: 3920-3929.

77. Karandashev VK, Turanov AN, Orlova TA, Lezhnev AE, Nosenko SV, Zolotareva NI, Moskvitina IR. Use of the inductively coupled plasma mass spectrometry for element analysis of environmental objects. Inorg Mater 2008, 44: 1491-1500.

78. Liu Y, Shipton MK, Ryan J, Kaufman ED, Franzen S, Feldheim DL. Synthesis, Stability, and Cellular Internalization of Gold Nanoparticles Containing Mixed Peptide-Poly(ethylene glycol) Monolayers. Anal Chem 2007, 79: 2221-2229.

79. Ryan JA, Overton KW, Speight ME, Oldenburg CN, Loo L, Robarge W, Franzen S, Feldheim DL. Cellular Uptake of Gold Nanoparticles Passivated with BSA-SV4O Large T Antigen Conjugates. Anal Chem 2007, 79: 9150-9159.

80. Fabricius A-L, Duester L, Meermann B, Ternes TA. ICP-MS-based characterization of inorganic nanoparticles-sample preparation and off-line fractionation strategies. Anal Bioanal Chem 2014, 406: 467-479.

81. Peters RJB, Rivera ZH, van Bemmel G, Marvin HJP, Weigel S, Bouwmeester H. Development and validation of single particle ICP-MS for sizing and quantitative determination of nano-silver in chicken meat. Anal Bioanal Chem 2014, 406: 3875-3885. 
82. Wang P, Lombi E, Sun S, Scheckel KG, Malysheva A, McKenna BA, Menzies NW, Zhao F-J, Kopittke PM. Characterizing the uptake, accumulation and toxicity of silver sulfide nanoparticles in plants. Environ Sci: Nano 2017, 4: 448-460.

83. Miyashita S-i, Groombridge AS, Fujii S-i, Takatsu A, Chiba K, Inagaki K. Time-resolved ICP-MS measurement: a new method for elemental and multiparametric analysis of single cells. Anal Sci 2014, 30: 219-224.

84. Mueller L, Traub H, Jakubowski N, Drescher D, Baranov VI, Kneipp J. Trends in single-cell analysis by use of ICP-MS. Anal Bioanal Chem 2014, 406: 6963-6977.

85. Mitrano DM, Lesher EK, Bednar A, Monserud J, Higgins CP, Ranville JF. Detecting nanoparticulate silver using single-particle inductively coupled plasma-mass spectrometry. Environ Toxicol Chem 2012, 31: 115-121.

86. Montaño MD, Olesik JW, Barber AG, Challis K, Ranville JF. Single Particle ICP-MS: Advances toward routine analysis of nanomaterials. Anal Bioanal Chem 2016, 408: 5053-5074.

87. Gray EP, Coleman JG, Bednar AJ, Kennedy AJ, Ranville JF, Higgins CP. Extraction and Analysis of Silver and Gold Nanoparticles from Biological Tissues Using Single Particle Inductively Coupled Plasma Mass Spectrometry. Environ Sci Technol 2013, 47: 14315-14323.

88. Coleman JG, Kennedy AJ, Bednar AJ, Ranville JF, Laird JG, Harmon AR, Hayes CA, Gray EP, Higgins $C P$, Lotufo $G$, Steevens JA. Comparing the effects of nanosilver size and coating variations on bioavailability, internalization, and elimination, using Lumbriculus variegatus. Environ Toxicol Chem 2013, 32: 2069-2077.

89. Loeschner K, Navratilova J, Grombe R, Linsinger TPJ, Købler C, Mølhave K, Larsen EH. Inhouse validation of a method for determination of silver nanoparticles in chicken meat based on asymmetric flow field-flow fractionation and inductively coupled plasma mass spectrometric detection. Food Chem 2015, 181: 78-84.

90. Roman M, Rigo C, Castillo-Michel H, Munivrana I, Vindigni V, Mičetić I, Benetti F, Manodori L, Cairns WRL. Hydrodynamic chromatography coupled to single-particle ICP-MS for the simultaneous characterization of AgNPs and determination of dissolved Ag in plasma and blood of burn patients. Anal Bioanal Chem 2016, 408: 5109-5124.

91. Becker JS, Matusch A, Wu B. Bioimaging mass spectrometry of trace elements - recent advance and applications of LA-ICP-MS: A review. Anal Chim Acta 2014, 835: 1-18.

92. Pozebon D, Scheffler GL, Dressler VL. Recent applications of laser ablation inductively coupled plasma mass spectrometry (LA-ICP-MS) for biological sample analysis: a follow-up review. J Anal At Spectrom 2017.

93. Böhme S, Stärk H-J, Kühnel D, Reemtsma T. Exploring LA-ICP-MS as a quantitative imaging technique to study nanoparticle uptake in Daphnia magna and zebrafish (Danio rerio) embryos. Anal Bioanal Chem 2015, 407: 5477-5485.

94. Managh AJ, Hutchinson RW, Riquelme P, Broichhausen C, Wege AK, Ritter U, Ahrens N, Koehl GE, Walter L, Florian C, Schlitt HJ, Reid HJ, Geissler EK, Sharp BL, Hutchinson JA. Laser Ablation-Inductively Coupled Plasma Mass Spectrometry: An Emerging Technology for Detecting Rare Cells in Tissue Sections. J Immunol 2014, 193: 2600.

95. Chen S, Xiong C, Liu H, Wan Q, Hou J, He Q, Badu-Tawiah A, Nie Z. Mass spectrometry imaging reveals the sub-organ distribution of carbon nanomaterials. Nat Nano 2015, 10: 176-182. 96. Yan B, Kim ST, Kim CS, Saha K, Moyano DF, Xing Y, Jiang Y, Roberts AL, Alfonso FS, Rotello VM, Vachet RW. Multiplexed Imaging of Nanoparticles in Tissues Using Laser Desorption/Ionization Mass Spectrometry. JACS 2013, 135: 12564-12567. 
97. Zhu Z-J, Ghosh PS, Miranda OR, Vachet RW, Rotello VM. Multiplexed Screening of Cellular Uptake of Gold Nanoparticles Using Laser Desorption/Ionization Mass Spectrometry. JACS 2008, 130: 14139-14143.

98. Hou S, Sikora KN, Tang R, Liu Y, Lee Y-W, Kim ST, Jiang Z, Vachet RW, Rotello VM. Quantitative Differentiation of Cell Surface-Bound and Internalized Cationic Gold Nanoparticles Using Mass Spectrometry. ACS Nano 2016, 10: 6731-6736.

99. Moore KL, Lombi E, Zhao F-J, Grovenor CRM. Elemental imaging at the nanoscale: NanoSIMS and complementary techniques for element localisation in plants. Anal Bioanal Chem 2012, 402: 3263-3273.

100. Vickerman JC. Secondary ion mass spectrometry-basic concepts, instrumental aspects, applications and trends. A. Benninghoven, F. G. Rudenauer and H. W. Werner, Wiley, New York, 1987, 1277 pages. Surf Interface Anal 1987, 10: 435-435.

101. Moore KL, Chen Y, van de Meene AML, Hughes L, Liu W, Geraki T, Mosselmans F, McGrath SP, Grovenor C, Zhao F-J. Combined NanoSIMS and synchrotron X-ray fluorescence reveal distinct cellular and subcellular distribution patterns of trace elements in rice tissues. New Phytologist 2014, 201: 104-115.

102. Lopes VR, Loitto V, Audinot J-N, Bayat N, Gutleb AC, Cristobal S. Dose-dependent autophagic effect of titanium dioxide nanoparticles in human $\mathrm{HaCaT}$ cells at non-cytotoxic levels. $J$

Nanobiotechnol 2016, 14: 22.

103. Georgantzopoulou A, Serchi T, Cambier S, Leclercq CC, Renaut J, Shao J, Kruszewski M, Lentzen E, Grysan P, Eswara S, Audinot J-N, Contal S, Ziebel J, Guignard C, Hoffmann L, Murk AJ, Gutleb AC. Effects of silver nanoparticles and ions on a co-culture model for the gastrointestinal epithelium. Part Fibre Toxicol 2016, 13: 9.

104. Proetto MT, Anderton CR, Hu D, Szymanski CJ, Zhu Z, Patterson JP, Kammeyer JK, Nilewski LG, Rush AM, Bell NC, Evans JE, Orr G, Howell SB, Gianneschi NC. Cellular Delivery of Nanoparticles Revealed with Combined Optical and Isotopic Nanoscopy. ACS Nano 2016, 10: 4046-4054.

105. Wang B, Feng W, Chai Z, Zhao Y. Probing the interaction at nano-bio interface using synchrotron radiation-based analytical techniques. Sci China Chem 2015, 58: 768-779.

106. Ferraro D, Tredici IG, Ghigna P, Castillio-Michel H, Falqui A, Di Benedetto C, Alberti G, Ricci V, Anselmi-Tamburini U, Sommi P. Dependence of the $\mathrm{Ce}(\mathrm{III}) / \mathrm{Ce}(\mathrm{IV})$ ratio on intracellular localization in ceria nanoparticles internalized by human cells. Nanoscale 2017, 9: 1527-1538.

107. Veronesi G, Deniaud A, Gallon T, Jouneau PH, Villanova J, Delangle P, Carriere M, Kieffer I, Charbonnier P, Mintz E, Michaud-Soret I. Visualization, quantification and coordination of Ag+ ions released from silver nanoparticles in hepatocytes. Nanoscale 2016, 8: 17012-17021.

108. Rashkow JT, Patel SC, Tappero R, Sitharaman B. Quantification of single-cell nanoparticle concentrations and the distribution of these concentrations in cell population. J R Soc Interface 2014, 11(94): 20131152.

109. James SA, Feltis BN, de Jonge MD, Sridhar M, Kimpton JA, Altissimo M, Mayo S, Zheng C, Hastings A, Howard DL, Paterson DJ, Wright PFA, Moorhead GF, Turney TW, Fu J. Quantification of ZnO Nanoparticle Uptake, Distribution, and Dissolution within Individual Human Macrophages. ACS Nano 2013, 7: 10621-10635.

110. de Jonge MD, Holzner C, Baines SB, Twining BS, Ignatyev K, Diaz J, Howard DL, Legnini D, Miceli A, McNulty I, Jacobsen CJ, Vogt S. Quantitative 3D elemental microtomography of Cyclotella meneghiniana at 400-nm resolution. Proc Nat Acad Sci 2010, 107: 15676-15680. 
111. Zhang J, Cai X, Zhang Y, Li X, Li W, Tian Y, Li A, Yu X, Fan C, Huang Q. Imaging cellular uptake and intracellular distribution of TiO2 nanoparticles. Anal Methods 2013, 5: 6611-6616.

112. Wang L, Zhang T, Li P, Huang W, Tang J, Wang P, Liu J, Yuan Q, Bai R, Li B, Zhang K, Zhao Y, Chen C. Use of Synchrotron Radiation-Analytical Techniques To Reveal Chemical Origin of SilverNanoparticle Cytotoxicity. ACS Nano 2015, 9: 6532-6547.

113. de Jonge MD, Ryan CG, Jacobsen CJ. X-ray nanoprobes and diffraction-limited storage rings: opportunities and challenges of fluorescence tomography of biological specimens. J Synchrotron Rad 2014, 21: 1031-1047.

114. Ho K-S, Chan W-T. Time-resolved ICP-MS measurement for single-cell analysis and on-line cytometry. J Anal At Spectrom 2010, 25: 1114-1122.

115. Zheng L-N, Wang $M$, Wang B, Chen H-Q, Ouyang H, Zhao Y-L, Chai Z-F, Feng W-Y.

Determination of quantum dots in single cells by inductively coupled plasma mass spectrometry. Talanta 2013, 116: 782-787.

116. Tsang C-N, Ho K-S, Sun H, Chan W-T. Tracking Bismuth Antiulcer Drug Uptake in Single Helicobacter pylori Cells. JACS 2011, 133: 7355-7357.

117. Beauchemin D. Environmental analysis by inductively coupled plasma mass spectrometry. Mass Spectrom Rev 2010, 29: 560-592.

118. Spitzer Matthew H, Nolan Garry P. Mass Cytometry: Single Cells, Many Features. Cell 2016, 165: 780-791.

119. Lou X, Zhang G, Herrera I, Kinach R, Ornatsky O, Baranov V, Nitz M, Winnik MA. PolymerBased Elemental Tags for Sensitive Bioassays. Angew Chem Int Ed 2007, 46: 6111-6114.

120. Bendall SC, Simonds EF, Qiu P, Amir el AD, Krutzik PO, Finck R, Bruggner RV, Melamed R, Trejo A, Ornatsky OI, Balderas RS, Plevritis SK, Sachs K, Pe'er D, Tanner SD, Nolan GP. Single-cell mass cytometry of differential immune and drug responses across a human hematopoietic continuum. Science 2011, 332: 687-96.

121. Schulz AR, Stanislawiak S, Baumgart S, Grützkau A, Mei HE. Silver nanoparticles for the detection of cell surface antigens in mass cytometry. Cytometry $A$ 2016: n/a-n/a.

122. Lin W, Hou Y, Lu Y, Abdelrahman Al, Cao P, Zhao G, Tong L, Qian J, Baranov V, Nitz M. A HighSensitivity Lanthanide Nanoparticle Reporter for Mass Cytometry: Tests on Microgels as a Proxy for Cells. Langmuir 2014, 30: 3142-3153.

123. Tong L, Lu E, Pichaandi J, Zhao G, Winnik MA. Synthesis of Uniform NaLnF4 (Ln: Sm to Ho) Nanoparticles for Mass Cytometry. J Phys Chem C 2016, 120: 6269-6280.

124. Yang Y-SS, Atukorale PU, Moynihan KD, Bekdemir A, Rakhra K, Tang L, Stellacci F, Irvine DJ. High-throughput quantitation of inorganic nanoparticle biodistribution at the single-cell level using mass cytometry. Nat Comms 2017, 8: 14069.

125. Goodhew PJ, Humphreys J, Beanland R. Electron Microscopy and Analysis, Third Edition. CRC Press: 2000.

126. James LRA, Sluyter R, Dillon CT, Ralph SF. Effects of Gold Nanoparticles and Gold Antiarthritic Compounds on Inflammation Marker Expression in Macrophages. Aust. J Chem. 2017, just accepted.

127. Patri A, Umbreit T, Zheng J, Nagashima K, Goering P, Francke-Carroll S, Gordon E, Weaver J, Miller T, Sadrieh N, McNeil S, Stratmeyer M. Energy dispersive X-ray analysis of titanium dioxide nanoparticle distribution after intravenous and subcutaneous injection in mice. J Appl Toxicol 2009, 29: 662-672. 
128. Zheng J, Nagashima K, Parmiter D, de la Cruz J, Patri AK. SEM X-Ray Microanalysis of Nanoparticles Present in Tissue or Cultured Cell Thin Sections. In Characterization of Nanoparticles Intended for Drug Delivery, McNeil SE (Ed). Humana Press: Totowa, NJ, 2011; pp 93-99.

129. Havrdova M, Polakova K, Skopalik J, Vujtek M, Mokdad A, Homolkova M, Tucek J, Nebesarova J, Zboril R. Field emission scanning electron microscopy (FE-SEM) as an approach for nanoparticle detection inside cells. Micron 2014, 67: 149-154.

130. Cho EC, Xie J, Wurm PA, Xia Y. Understanding the Role of Surface Charges in Cellular Adsorption versus Internalization by Selectively Removing Gold Nanoparticles on the Cell Surface with $\mathrm{I}_{2} / \mathrm{KI}$ Etchant. Nano Lett 2009, 9: 1080-1084.

131. Cho EC, Au L, Zhang Q, Xia Y. The effects of size, shape, and surface functional group of gold nanostructures on their adsorption and internalization by cells. Small 2010, 6 .

132. Cardozo RH, Edelman IS, Moore FD. Sodium thiosulfate dilution as a measure of the volume of fluid outside of body cells. Surgical Forum 1951: 606]611.

133. Ray PC, Yu H, Fu PP. Toxicity and Environmental Risks of Nanomaterials: Challenges and Future Needs. J Environ Sci Health C Environ Carcinog Ecotoxicol Rev 2009, 27: 1-35.

134. Gräfe M, Donner E, Collins RN, Lombi E. Speciation of metal(loid)s in environmental samples by X-ray absorption spectroscopy: A critical review. Anal Chim Acta 2014, 822: 1-22.

135. Ivask A, Scheckel KG, Kapruwan P, Stone V, Yin H, Voelcker NH, Lombi E. Complete transformation of $\mathrm{ZnO}$ and $\mathrm{CuO}$ nanoparticles in culture medium and lymphocyte cells during toxicity testing. Nanotoxicology 2017, 11: 150-156.

This article is protected by copyright. All rights reserved. 

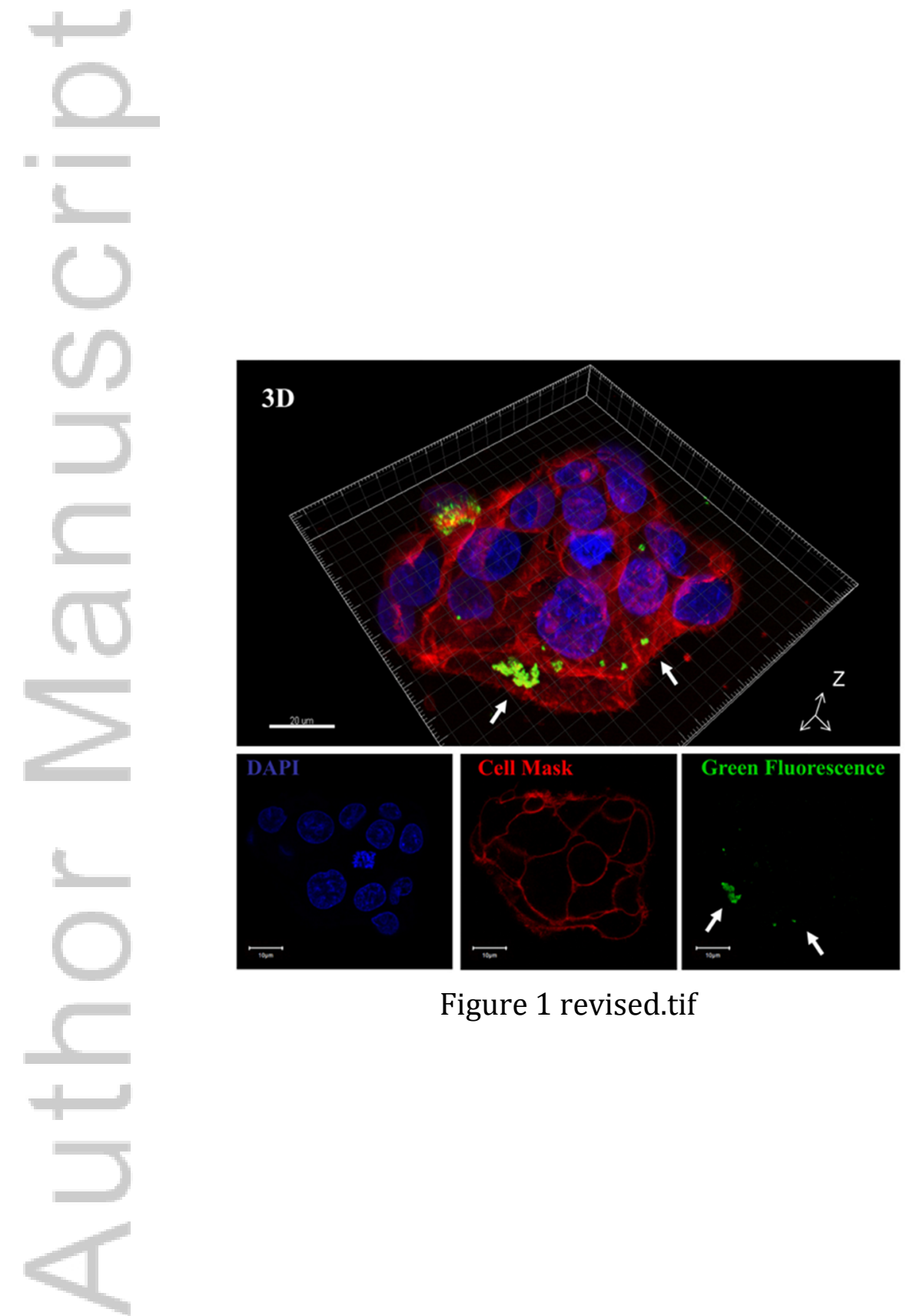

Figure 1 revised.tif

This article is protected by copyright. All rights reserved. 

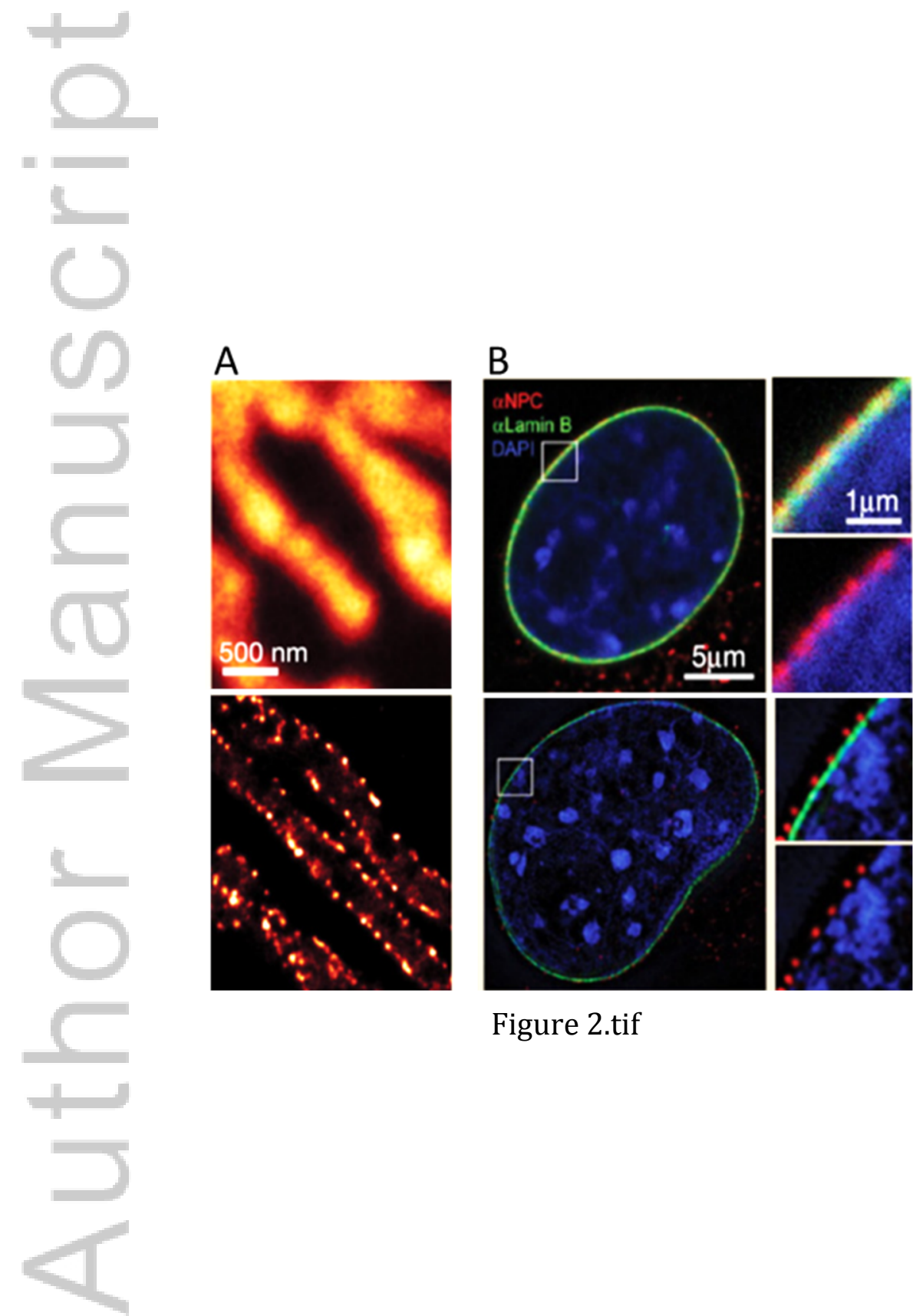

Figure 2.tif

This article is protected by copyright. All rights reserved. 


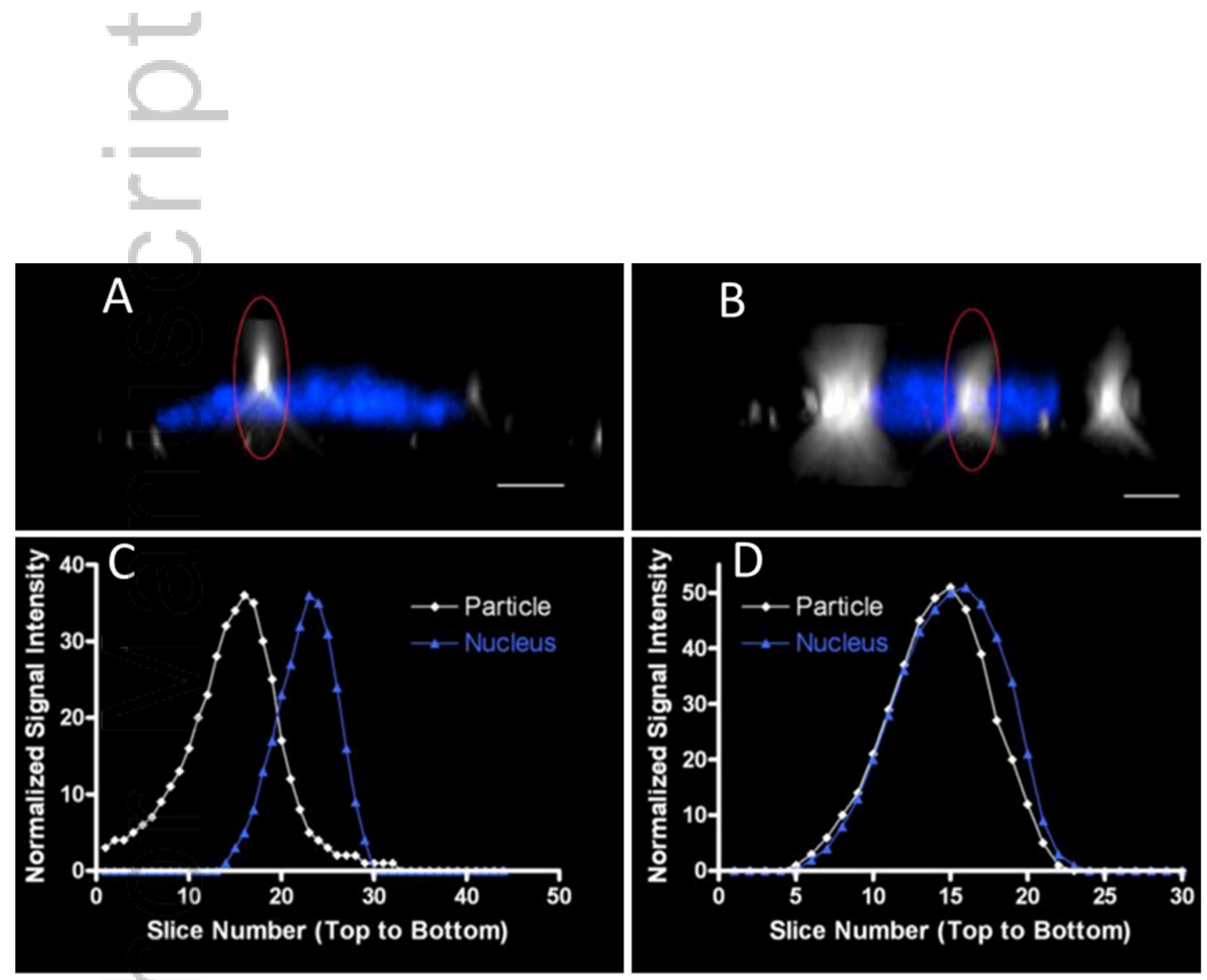

Figure 3.tif

This article is protected by copyright. All rights reserved. 




This article is protected by copyright. All rights reserved. 


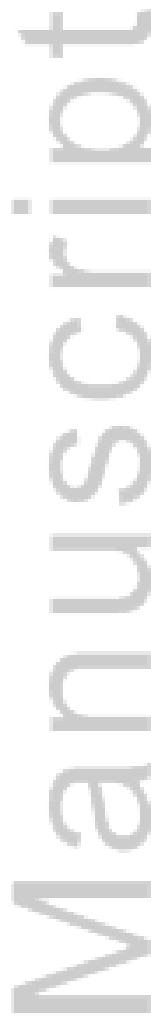

(

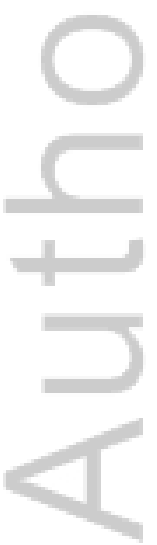

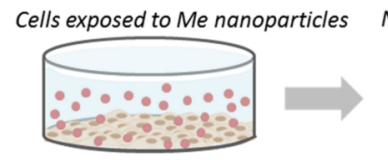

Cells and particles digested

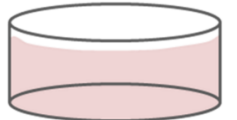

Non-attached nanoparticles removed

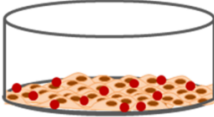

Calculation of nanoparticles in each cell:

Conentration (g/L) of

$\begin{aligned} & \text { Mass }(g) \text { of Me } \\ & \text { per cell }\end{aligned} \quad=\frac{\text { element in digested cells }}{\text { Cell concentration (cells/L) }}$

Nanoparticles per cell $=\frac{\text { Mass }(\mathrm{g}) \text { of Me per cell }}{\text { Mass (g) of Me in a nanopartic }}$

Figure 5.tif

This article is protected by copyright. All rights reserved. 

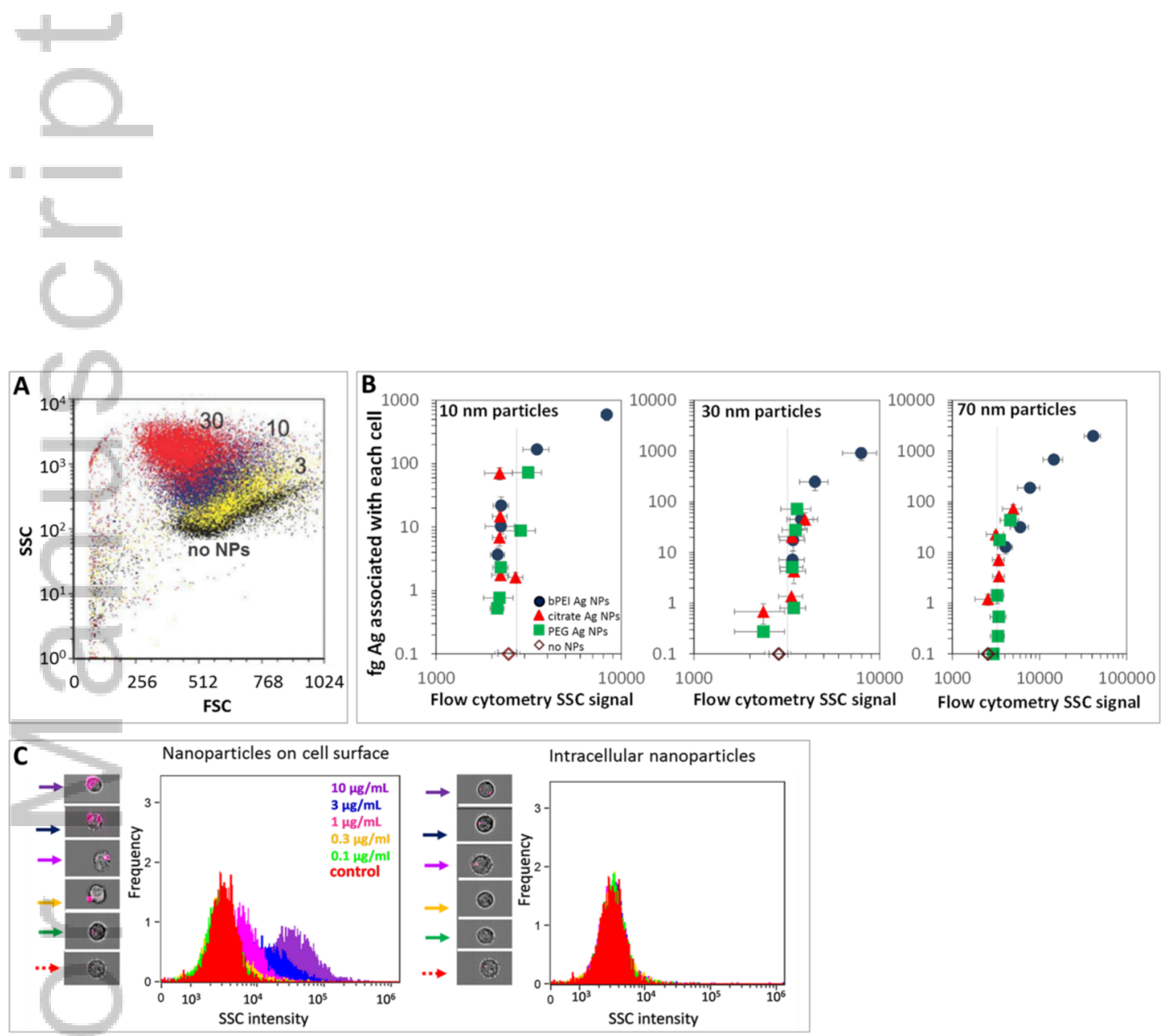

Figure 6.tif

This article is protected by copyright. All rights reserved. 


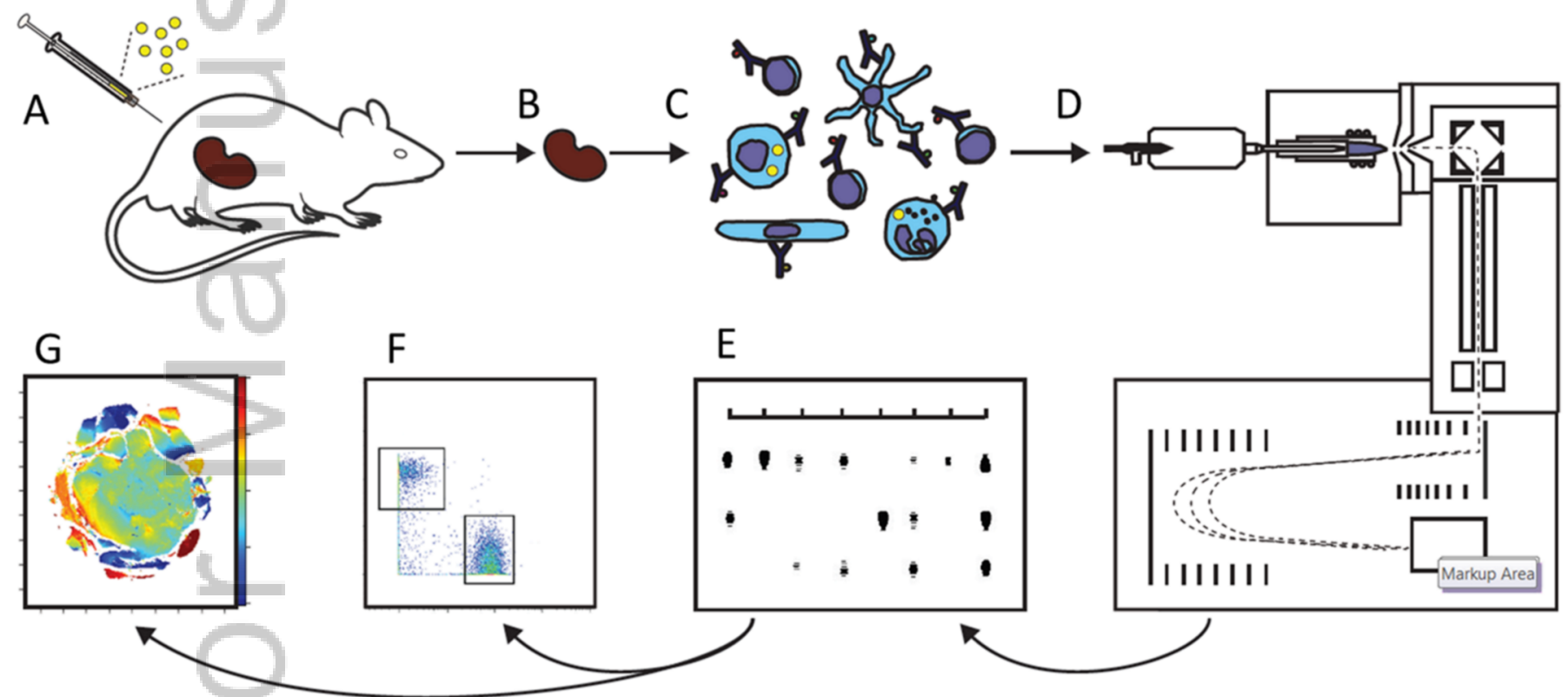

Figure 7.tif

This article is protected by copyright. All rights reserved. 




Figure 8 revised.tif

This article is protected by copyright. All rights reserved. 



B

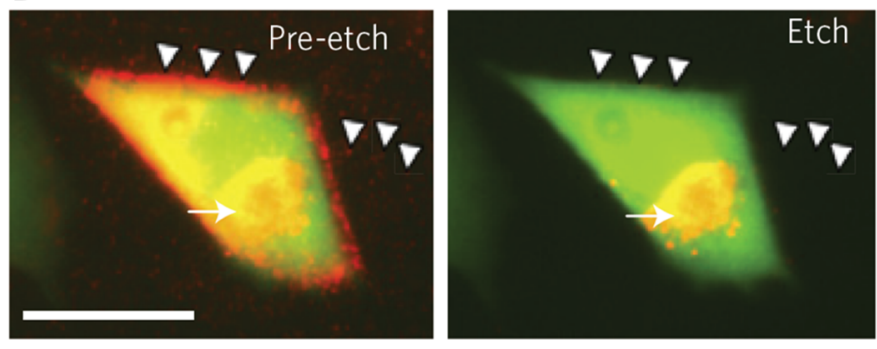

Figure 9.tif

This article is protected by copyright. All rights reserved. 

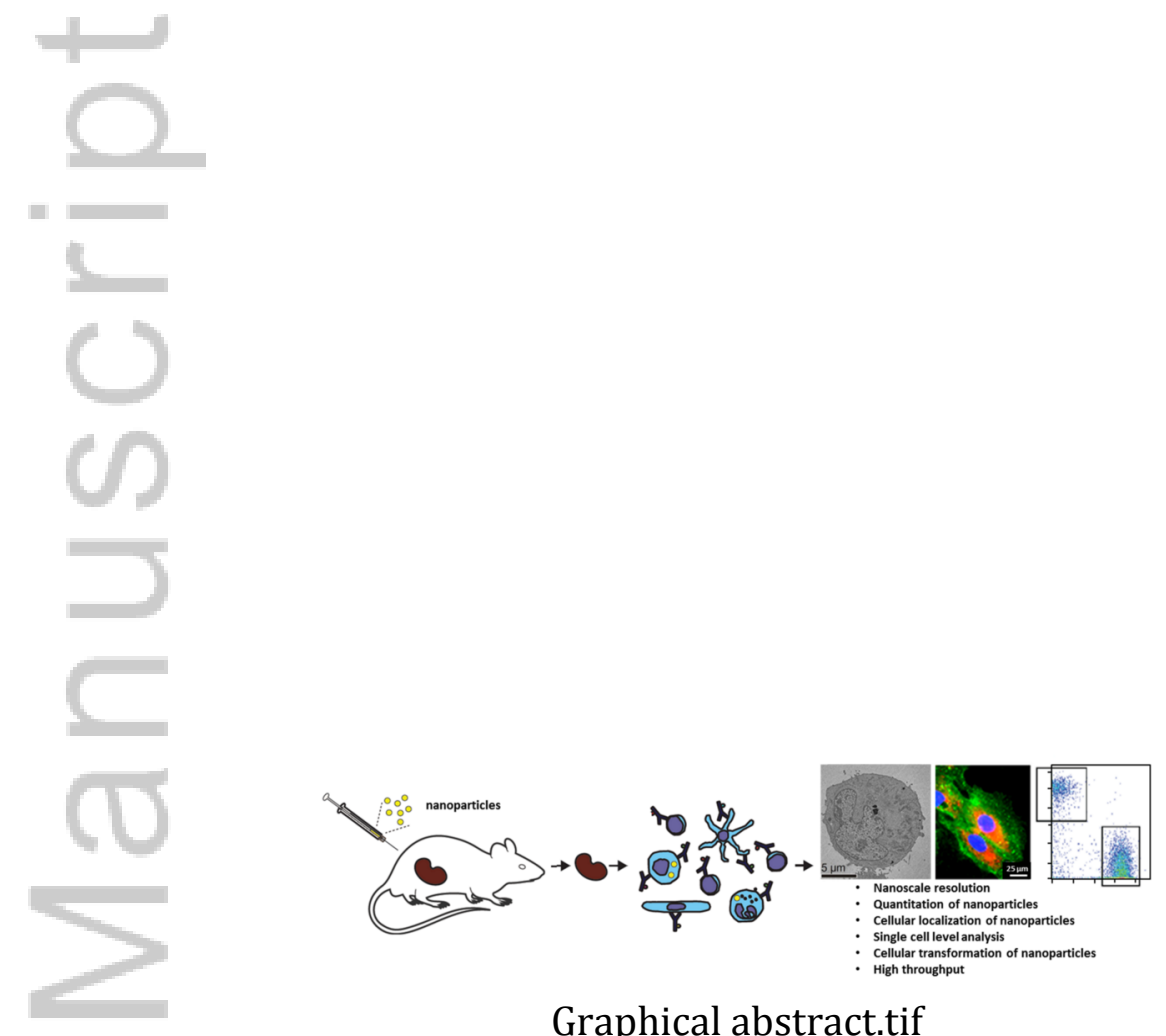

Graphical abstract.tif

This article is protected by copyright. All rights reserved. 